NASA/TM-2000-209891, Vol. 87

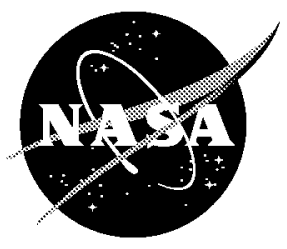

Technical Report Series on the Boreal Ecosystem-Atmosphere Study (BOREAS)

Forrest G. Hall, Editor

\title{
Volume 87
}

\section{BOREAS BOREAS Level-1B MAS Imagery: At-sensor Radiance, Relative $X$ and $Y$ Coordinates}

Richard Strub, Raytheon ITSS

Paul Hubanks, RDC

Jeffrey A. Newcomer, Raytheon ITSS

Stephen Ungar, NASA Goddard Space Flight Center, Greenbelt, Maryland

National Aeronautics and

Space Administration

Goddard Space Flight Center

Greenbelt, Maryland 20771 
The NASA STI Program Office ... in Profile

Since its founding, NASA has been dedicated to the advancement of aeronautics and space science. The NASA Scientific and Technical Information (STI) Program Office plays a key part in helping NASA maintain this important role.

The NASA STI Program Office is operated by Langley Research Center, the lead center for NASA's scientific and technical information. The NASA STI Program Office provides access to the NASA STI Database, the largest collection of aeronautical and space science STI in the world. The Program Office is also NASA's institutional mechanism for disseminating the results of its research and development activities. These results are published by NASA in the NASA STI Report Series, which includes the following report types:

- TECHNICAL PUBLICATION. Reports of completed research or a major significant phase of research that present the results of NASA programs and include extensive data or theoretical analysis. Includes compilations of significant scientific and technical data and information deemed to be of continuing reference value. NASA's counterpart of peer-reviewed formal professional papers but has less stringent limitations on manuscript length and extent of graphic presentations.

- TECHNICAL MEMORANDUM. Scientific and technical findings that are preliminary or of specialized interest, e.g., quick release reports, working papers, and bibliographies that contain minimal annotation. Does not contain extensive analysis.

- CONTRACTOR REPORT. Scientific and technical findings by NASA-sponsored contractors and grantees.
- CONFERENCE PUBLICATION. Collected papers from scientific and technical conferences, symposia, seminars, or other meetings sponsored or cosponsored by NASA.

- SPECIAL PUBLICATION. Scientific, technical, or historical information from NASA programs, projects, and mission, often concerned with subjects having substantial public interest.

- TECHNICAL TRANSLATION. English-language translations of foreign scientific and technical material pertinent to NASA's mission.

Specialized services that complement the STI Program Office's diverse offerings include creating custom thesauri, building customized databases, organizing and publishing research results ... even providing videos.

For more information about the NASA STI Program Office, see the following:

- Access the NASA STI Program Home Page at http://www.sti.nasa.gov/STI-homepage.html

- E-mail your question via the Internet to help@sti.nasa.gov

- Fax your question to the NASA Access Help Desk at (301) 621-0134

- Telephone the NASA Access Help Desk at (301) 621-0390

- Write to:

NASA Access Help Desk

NASA Center for AeroSpace Information 7121 Standard Drive Hanover, MD 21076-1320 
NASA/TM-2000-209891, Vol. 87

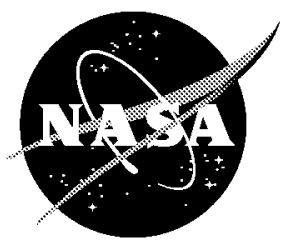

Technical Report Series on the Boreal Ecosystem-Atmosphere Study (BOREAS)

Forrest G. Hall, Editor

\section{Volume 87}

\section{BOREAS BOREAS Level-1B MAS Imagery: At-sensor Radiance, Relative $X$ and $Y$ Coordinates}

Richard Strub, Raytheon ITSS

Paul Hubanks, RDC

Jeffrey A. Newcomer, Raytheon ITSS

Stephen Ungar, NASA Goddard Space Flight Center, Greenbelt, Maryland

National Aeronautics and

Space Administration

Goddard Space Flight Center

Greenbelt, Maryland 20771 


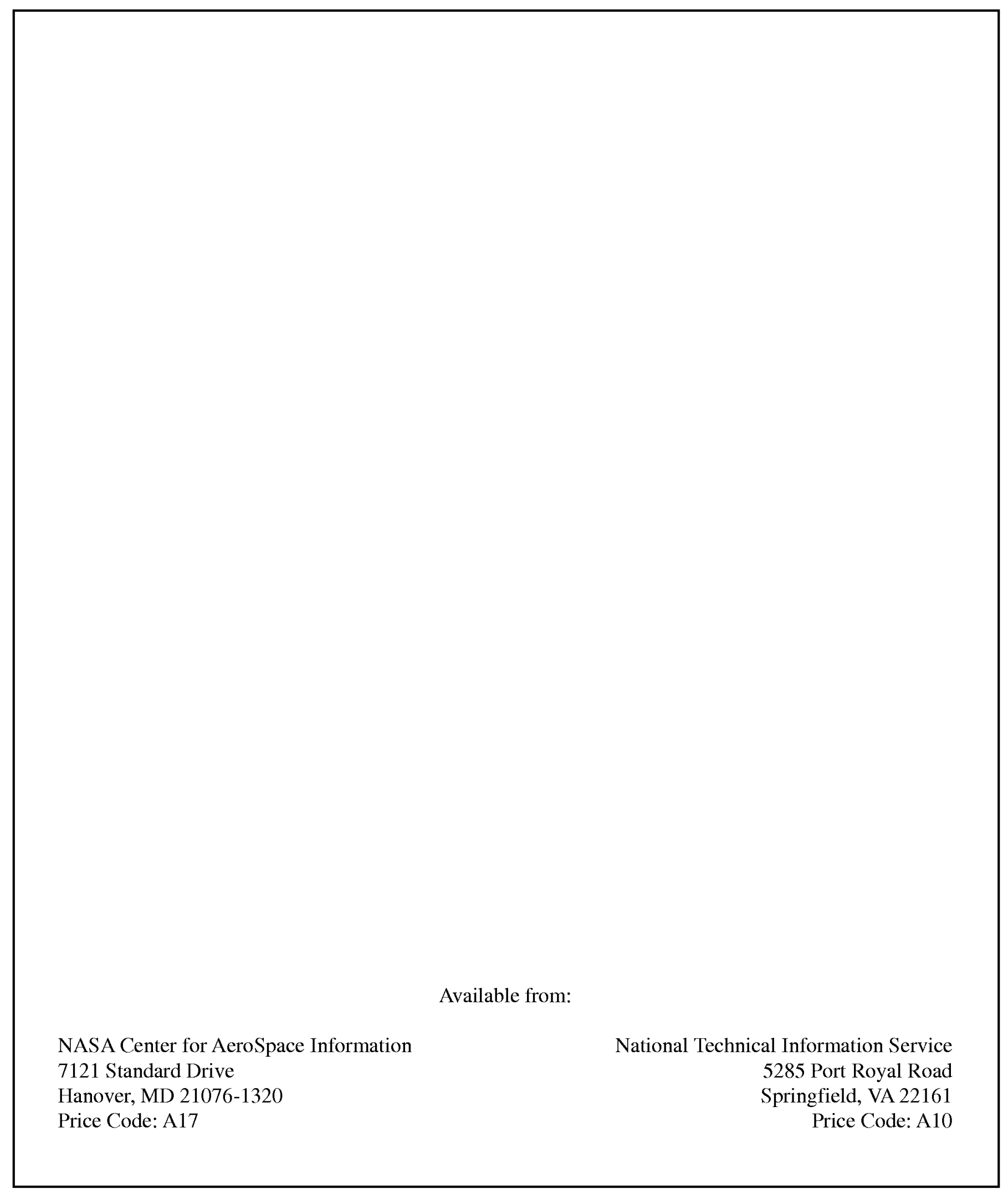




\title{
BOREAS Level-1b MAS Imagery: At-sensor Radiance, Relative X and Y Coordinates
}

\author{
Richard Strub, Paul Hubanks Jeffrey A. Newcomer, Stephen G. Ungar
}

\section{Summary}

For BOREAS, the MAS images, along with the other remotely sensed data, were collected to provide spatially extensive information over the primary study areas. This information includes detailed land cover and biophysical parameter maps such as fPAR and LAI. Collection of the MAS images occurred over the study areas during the 1994 field campaigns. The level-1b MAS data cover the dates of 21-Jul-1994, 24-Jul-1994, 04-Aug-1994, and 08-Aug-1994. The data are not geographically/geometrically corrected; however, files of relative $\mathrm{X}$ and $\mathrm{Y}$ coordinates for each image pixel were derived by using the C-130 INS data in a MAS scan model. The data are provided in binary image format files.

Note that the level-1b MAS data are not contained on the BOREAS CD-ROM set. An inventory listing file is supplied on the CD-ROM to inform users of the data that were collected. See Section 15 for information about how to acquire actual level-1b MAS images.

\section{Table of Contents}

1) Data Set Overview

2) Investigator(s)

3) Theory of Measurements

4) Equipment

5) Data Acquisition Methods

6) Observations

7) Data Description

8) Data Organization

9) Data Manipulations

10) Errors

11) Notes

12) Application of the Data Set

13) Future Modifications and Plans

14) Software

15) Data Access

16) Output Products and Availability

17) References

18) Glossary of Terms

19) List of Acronyms

20) Document Information

\section{Data Set Overview}

\subsection{Data Set Identification \\ BOREAS Level-1b MAS Imagery: At-sensor Radiance, Relative X and Y Coordinates}

\subsection{Data Set Introduction}

The BOReal Ecosystem-Atmosphere Study (BOREAS) Staff Science effort covered those activities that were BOREAS community level activities or required uniform data collection procedures across sites and time. These activities included the acquisition of the relevant aircraft image data. Data from the Moderate Resolution Imaging Spectroradiometer (MODIS) Airborne Simulator (MAS) onboard the National Aeronautics and Space Administration (NASA) C-130 aircraft were acquired by staff of the 
Medium Altitude Aircraft Branch at NASA Ames Research Center (ARC) and provided for use by BOREAS researchers.

BOREAS Information System (BORIS) personnel worked with MAS personnel at NASA Goddard Space Flight Center (GSFC) in processing the MAS and related C-130 navigation data to derive and archive the 12-band level-1b MAS imagery.

\subsection{Objective/Purpose}

For BOREAS, the MAS data, along with the other remotely sensed images, were collected in order to provide spatially extensive information over the primary study areas. This information includes detailed land cover and biophysical parameter maps such as fraction of Photosynthetically Active Radiation (fPAR), and Leaf Area Index (LAI). The MAS data were also to serve as test data sets for the MODIS Land Group (MODLAND) in exercising its parameter derivation algorithms.

\subsection{Summary of Parameters}

Level-1b MAS data in the BORIS contain the following parameters:

Descriptive information as American Standard Code for Information Interchange (ASCII) text records, at-sensor radiance values for image bands 1 to 12 , relative $\mathrm{X}$ and $\mathrm{Y}$ pixel coordinates, and per pixel view zenith and azimuth angles.

\subsection{Discussion}

BORIS staff created the level-1b MAS imagery by: 1) extracting aircraft location and attitude information from BOREAS level-0 C-130 navigation data, 2) combining MAS image and C-130 navigation data to make a Hierarchical Data Format (HDF) file, 3) extracting image and ancillary information from the HDF file and reformatting it into a band sequential (BSQ) format 8-mm tape product for distribution, and 4) creating a descriptive inventory of the MAS data product in the BORIS data base.

\subsection{Related Data Sets}

BORIS Level-2 MAS Surface Reflectance and Temperature Images in BSQ Format BOREAS RSS-02 Level-1b ASAS Image Data: At-sensor Radiance in BSQ Format BOREAS Level-2 NS001 TMS Images: Reflectance and Temperatures in BSQ Format BOREAS Level-1b TIMS Imagery: At Sensor Radiance in BSQ Format BOREAS Level-3a Landsat TM Imagery: Scaled At-sensor Radiance in BSQ Format

\section{Investigator(s)}

\subsection{Investigator(s) Name and Title} BOREAS Staff Science

\subsection{Title of Investigation}

BOREAS Staff Science Aircraft Data Acquisition Program

\subsection{Contact Information}

\section{Contact 1:}

Stephen G. Ungar

Code 923

NASA GSFC

Greenbelt, MD 20771

(301) 286-4007

(301) 286-0239 (fax)

ungar@highwire.gsfc.nasa.gov 


\section{Contact 2:}

Jeffrey A. Newcomer

Raytheon ITSS

Code 923

NASA GSFC

Greenbelt, MD 20771

(301) 286-7858

(301) 286-0239 (fax)

Jeffrey.Newcomer@gsfc.nasa.gov

\section{Theory of Measurements}

MODIS was developed as part of the Earth Observing System (EOS) to meet the scientific needs for global remote sensing of clouds, aerosols, water vapor, land, and ocean properties from space. MODIS is scheduled to be launched in 1998 on the EOS AM-1 platform (King et al., 1995). In support of MODIS remote sensing algorithm development, the MAS was developed by Daedalus Enterprises, Inc., for NASA's high-altitude ER-2 research aircraft, and is an outgrowth of the development of the Wildfire infrared imaging spectrometer. In a cooperative effort between the High Altitude Missions Branch at NASA ARC and the MODIS science team, Wildfire was converted to the MAS and upgraded over a series of several experiments, starting with the First International Satellite Cloud Climatology Project (ISCCP) Regional Experiment cirrus campaign (FIRE II) in November 1991.

The locations of the MAS spectral channels were chosen to enable a wide variety of earth science applications. Of the 50 MAS channels, 19 have corresponding channels on MODIS. The remaining MAS channels fill in the spectral region around MODIS locations and some provide unique coverage.

One application of the MAS solar channels is the study of cloud properties at high spatial resolution. The majority of the molecular absorption in the shortwave region of the solar spectrum is due to water vapor, with some ozone absorption in the broad Chappuis band $(\sim 0.6 \mu \mathrm{m})$ continuum. The reflectance measurements in the 1.61, 2.13, and $3.74 \mu \mathrm{m}$ windows provide useful information on the cloud droplet size. Reflectance measurements in the visible wavelength region, in contrast, show little variation with droplet size and can thus be used to retrieve cloud optical thickness (cf. Twomey and Cocks, 1982; Nakajima and King, 1990). The reflectance at 0.94 بm is attenuated by atmospheric water vapor; these measurements, in conjunction with spectrally close atmospheric window reflectances, can provide an estimate of the total precipitable water in cloud-free regions (Kaufman and Gao, 1992).

Cloud properties can also be estimated from the thermal bands. In the 3.7-um window, both solar reflected and thermal emitted radiation are significant, though the use of the reflectance for cloud droplet size retrieval is seen to be much more sensitive than the thermal component. $\mathrm{CO}_{2}$ absorption is important around $4.3 \mu \mathrm{m}$ and at wavelengths greater than about $13 \mu \mathrm{m}$. The MAS bands in these spectral regions can indicate vertical changes of temperature. The 4.82- to 5.28-um channels are useful for investigating both horizontal and vertical distributions of moisture. Low-level moisture information is available in the split window measurements at 11.02 and $11.96 \mu \mathrm{m}$, and correction for moisture attenuation in the infrared windows at 3.90, 11.02, and $11.96 \mu \mathrm{m}$ enables estimation of sea surface skin temperature (Smith et al., 1995).

The MAS infrared spectral bands enable the study of cloud properties at high spatial resolution. Products include cloud thermodynamic phase (ice vs. water, clouds vs. snow), cloud top properties, and cloud fraction. The cloud top properties (height, temperature, and effective emissivity) can be investigated using the $\mathrm{CO}_{2}$ slicing algorithm (Wylie et al., 1994) that corrects for cloud semitransparency with the MAS infrared $\mathrm{CO}_{2}$ bands at 11.02, 13.23, and $13.72 \mu \mathrm{m}$. Cloud phase can be obtained using MAS 8.60-, 11.02-, and 11.96-um brightness temperature differencing (Strabala et al., 1994) as well as by using visible reflection function techniques (King et al., 1992) utilizing ratios of the MAS 1.61- and 0.66-um bands. 
In addition to the remote sensing of cloud radiative and microphysical properties, the MAS is of value for the remote sensing of land and water properties under channel clear-sky conditions. MAS visible and near-infrared channels have been used to estimate suspended sediment concentration in near-shore waters and to identify water types (Moeller et al., 1993; Huh et al., 1995). Land vegetation properties can also be studied.

In a cooperative effort between Dr. M. King (Code 900, NASA GSFC), BOREAS scientists, and the NASA ARC C-130 missions staff, the MAS was installed into the NASA C-130 aircraft for use during the 1994 summer field campaign of BOREAS.

\section{Equipment}

\subsection{Sensor/Instrument Description}

In support of MODIS remote sensing algorithm development, the MAS was developed by Daedalus Enterprises, Inc., for NASA's high-altitude ER-2 research aircraft. Over the past several years, upgrades included new detector arrays, grating modifications, an improved broadband lens for the infrared channels, new Dewars, and various electronics improvements, all of which resulted in improved in-flight radiometric performance.

The overall goal was to modify the spectral coverage and gains of the MAS in order to emulate as many of the MODIS spectral channels as possible. With its much higher spatial resolution ( $50 \mathrm{~m} \mathrm{vs}$. 250-1000 $\mathrm{m}$ for MODIS), the MAS is able to provide unique information on the small-scale distribution of various geophysical parameters. Originally and for the BOREAS deployment, the MAS used a 12-channel, 8-bit data system that somewhat constrained the full benefit of having a 50-channel scanning spectrometer. Beginning in January 1995, a 50-channel, 16-bit digitizer was used, which greatly enhanced the capability of the MAS to simulate MODIS data over a wide range of environmental conditions. The 12 data channels configured for the BOREAS Intensive Field Campaign (IFC)-2 C-130 flights were:

$\begin{array}{ccc}\text { Data } & \text { MAS Spectral } & \begin{array}{c}\text { Center } \\ \text { Wavelength }(\mu \mathrm{m})\end{array} \\ ----- & -------- & ----------- \\ 01 & 01 & 0.547 \\ 02 & 02 & 0.664 \\ 03 & 04 & 0.745 \\ 04 & 05 & 0.786 \\ 05 & 06 & 0.834 \\ 06 & 07 & 0.875 \\ 07 & 09 & 0.945 \\ 08 & 10 & 1.623 \\ 09 & 20 & 2.142 \\ 10 & 32 & 3.900 \\ 11 & 45 & 11.002 \\ 12 & 46 & 12.032\end{array}$

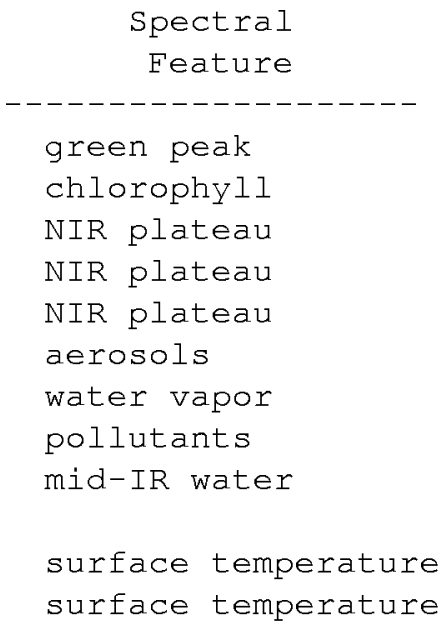

A total of 716 Earth-viewing pixels are acquired per scan at a scan rate of $6.25 \mathrm{~Hz}$. Information provided by the aircraft inertial navigation system is used to adjust the timing of the digitizer, providing up to 3.5 degrees of roll compensation, in 0.03 degree increments.

\subsubsection{Collection Environment}

As part of the BOREAS Staff Science data collection effort, the ARC Medium Altitude Aircraft Branch collected the 12-band MAS multispectral scanner data. The MAS was flown on NASA's C-130 aircraft during BOREAS (see the BOREAS Experiment Plan for flight pattern details and objectives). The MAS was flown at medium altitudes aboard NASA's C-130 aircraft based at the NASA ARC and provided 20-meter spatial resolution at nadir at an altitude of 7,500 meters. 


\subsubsection{Source/Platform}

For the BOREAS missions in 1994, the MAS was mounted in the NASA C-130 aircraft operated by the NASA ARC.

\subsubsection{Source/Platform Mission Objectives}

The C-130 mission objectives for BOREAS were to acquire high-resolution digital imagery with a variety of sensors during optimally clear days of the BOREAS field effort in 1994.

\subsubsection{Key Variables}

Emitted radiation, reflected radiation, and temperature.

\subsubsection{Principles of Operation}

The optical system of the MAS is composed of a configuration of dichroic beam splitters, collimating mirrors, folding mirrors, diffraction gratings, filters, lenses, and detector arrays. Both the spectrometer and fore optics portions are mounted to an aluminum optical baseplate assembly, which are pinned and mated.

A full face scan mirror canted 45 degrees to the along track direction directs light into an afocal Gregorian telescope followed by a fold mirror that directs light back through a field stop aperture. A 2.5-cm Pfund assembly paraboloid forms a collimated image of the aperture, which strikes a fold mirror that directs the incoming radiation upward into the aft optics spectrometer unit Thermal and dark visible references are viewed on the backscan rotation of the scan mirror. The thermal reference sources are two blackened copper plate temperature-controllable blackbodies. One blackbody is viewed prior to the Earth-viewing (active scan) portion of the scan, while the other is viewed following the active scan. The telescope alignment is maintained under the low temperature environment using Invar steel and aluminum structural components.

The spectrally broadband energy transmitted and reflected by the dichroics is dispersed onto the detector arrays from blazed diffraction gratings. The bandpass of a channel is determined by the geometry of the detector monolithic array and its location with respect to the grating.

The radiation transmitted by the first dichroic (D1) is reflected by a mirror and diffracted by grating G1 onto a filter and lens assembly that focuses the radiation onto a silicon photovoltaic array with channel response in the wavelength range from 0.55 to $0.95 \mu \mathrm{m}$ (channels 1-9). Part of the radiation reflected by D1 reflects off the second dichroic (D2) and is redirected by two fold mirrors, diffracted by grating $\mathrm{G} 2$, passed through a cold blocking filter, and focused onto an indium-antimonide (InSb) focal plane array assembly containing channels 10-25 (1.61 to $2.38 \mu \mathrm{m}$ ). From D2 the remainder of the spectrally separated energy strikes the third dichroic D3, part of which is reflected and enters port 3 , where it is redirected by two fold mirrors, diffracted by grating G3, and focused onto another InSb detector array that defines band-pass characteristics for channels 26-41 (2.96 to $5.28 \mathrm{um}$ ). The remainder of the energy from the scanner is transmitted through dichroic D3 into port 4, where it encounters a fold mirror, diffraction grating G4, and lens that focuses the thermal radiation onto three separate mercury-cadmium-telluride ( $\mathrm{HgCdTe}$ ) detector arrays, each with its own cold-filter to improve the signal-to-noise ratio in its respective wavelength range. Port 4 senses radiation in the wavelength range from 8.60 to $14.17 \mu \mathrm{m}$ (channels $42-50$ ). The InSb and $\mathrm{HgCdTe}$ detectors are cryogenically cooled by liquid nitrogen to $77 \mathrm{~K}$ in pressurized Dewars.

\subsubsection{Sensor/Instrument Measurement Geometry BOREAS IFC-2 MAS Instrument/Platform Specifications}

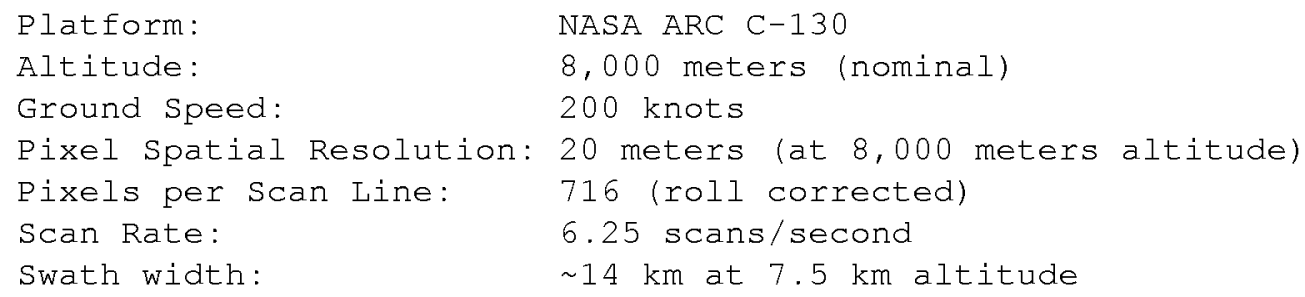


black paint. The calibration slope and intercept for the thermal channels are determined from this two point measurement. The blackbody sources are viewed during every scan of the mirror. The amount of energy received by the detector is related to the digitized count value by:

$$
\mathrm{Ib}=\mathrm{Sb}^{*} \mathrm{Cb}+\mathrm{ib}
$$

where: $\mathrm{Ib}$ is the radiance measured in each infrared spectral band $\mathrm{b}$

$\mathrm{Cb}$ is the count value representing the detector voltage response to the scene radiance

$\mathrm{Sb}$ is the slope

$\mathrm{ib}$ is the intercept

We assume a linear response, as laboratory determinations indicate fractional nonlinearity parameters of less than 0.0001 . The slope and intercept, and hence the calibration of counts to radiance, are calculated for each scan line using the count values recorded when viewing two on-board blackbody sources. Using:

w to indicate the warm blackbody, a to indicate the ambient blackbody, $m$ to indicate the MAS instrument,

and taking into account blackbody emissivity e, then

$$
\begin{aligned}
& \mathrm{Sb}=\mathrm{eb}(\mathrm{Iwb}-\mathrm{Iab}) /(\mathrm{Cwb}-\mathrm{Cab}) \\
& \mathrm{ib}=\mathrm{Iab}+(\mathrm{Im}-\mathrm{Iab})(1-\mathrm{eb})-\mathrm{Sb} \mathrm{C}^{*} \mathrm{ab}
\end{aligned}
$$

Blackbody count values are derived as the average of 12 FOVs across each blackbody surface during each scan, with the temperature of the blackbodies monitored by embedded thermistors. The emissivity of the blackbodies was obtained by viewing a well-characterized source in the laboratory, from which the emissivity was determined to be 0.94 and 0.98 for the longwave and shortwave infrared bands, respectively. For typical ocean scene temperatures, corrections for instrument radiation (IM) reflected by the MAS blackbodies are approximately $1.25^{\circ} \mathrm{C}$ for the longwave and $0.25^{\circ} \mathrm{C}$ for the shortwave bands, respectively.

Equivalent Planck radiances from the blackbodies are calculated for each spectral band using a spectral response weighted integral of the form

$$
\mathrm{Ib}(\mathrm{T})=\operatorname{Integral}[\mathrm{B}(\mathrm{h}, \mathrm{T}) \mathrm{F}(\mathrm{h}) \mathrm{dh}] / \text { Integral[F(h) dh] }
$$

where: $\mathrm{B}(\mathrm{h}, \mathrm{T})$ is the Planck function

$\mathrm{F}(\mathrm{h})$ is the spectral response for a given band

$h$ is wavelength

$\mathrm{T}$ is the blackbody temperature

This can be fitted to an adjusted Planck function for the range of Earth emitted temperatures by introducing coefficients $\mathrm{a} 0$ and al such that

$$
\mathrm{Ib}(\mathrm{T})=\mathrm{B}(\mathrm{hb}, \mathrm{a} 1 * \mathrm{~T}+\mathrm{a} 0),
$$

where hb is the central wavelength or wavenumber of band $b$.

\subsubsection{Specifications}

The following table shows the spectral and radiometric characteristics of each MAS channel in the complete 50-channel system. Spectral resolution, defined as the full-width at half-maximum bandwidth of the channel, ranges from around $40 \mathrm{~nm}$ in the visible and infrared to about $450 \mathrm{~nm}$ in the thermal infrared. 


\begin{tabular}{|c|c|c|c|c|c|c|c|}
\hline $\begin{array}{c}\text { MAS } \\
\text { channel }\end{array}$ & $\begin{array}{c}\text { MODIS } \\
\text { channel }\end{array}$ & $\begin{array}{c}\text { Central } \\
\text { Wavelength } \\
(\mu \mathrm{m})\end{array}$ & $\begin{array}{c}\text { Spectral } \\
\text { Res. } \\
(\mu \mathrm{m})\end{array}$ & $\begin{array}{l}\text { Equiv } \\
\text { Noise* }\end{array}$ & $\begin{array}{l}\text { Scene } \\
\text { Temp } \\
(\mathrm{K}) \star \star\end{array}$ & $\begin{array}{c}\text { Saturation } \\
\text { Level } \\
+\end{array}$ & $\begin{array}{l}\text { Signal-to } \\
\text { noise ratio** }\end{array}$ \\
\hline------- & ------- & ---------- & -------- & ------ & ----- & ---------- & ------------ \\
\hline 1 & 4 & 0.547 & 0.044 & 0.335 & & 867 & $45.2-1052$ \\
\hline 2 & 1 & 0.657 & 0.053 & 0.157 & & 1035 & $44.6-1948$ \\
\hline 3 & & 0.704 & 0.042 & 0.178 & & 1323. & $28.7-1586$ \\
\hline 4 & 15 & 0.745 & 0.041 & 0.180 & & 1412 & $21.5-1406$ \\
\hline 5 & & 0.786 & 0.041 & 0.254 & & 1638 & $12.4-912$ \\
\hline 6 & & 0.827 & 0.042 & 0.237 & & 1890 & $10.7-923$ \\
\hline 7 & 2 & 0.869 & 0.042 & 0.281 & & 1935 & $8.1-728$ \\
\hline 8 & 7 & 0.909 & 0.033 & 0.150 & & 314 & $14.9-1232$ \\
\hline 9 & 19 & 0.947 & 0.046 & 0.226 & & 1600 & $5.5-720$ \\
\hline 10 & 6 & 1.609 & 0.052 & 0.039 & & 892 & $4.5-397$ \\
\hline 11 & & 1.663 & 0.052 & 0.029 & & 272 & $5.8-570$ \\
\hline 12 & & 1.723 & 0.050 & 0.026 & & 252 & $5.1-659$ \\
\hline 13 & & 1.775 & 0.049 & 0.026 & & 244 & $2.8-624$ \\
\hline 14 & & 1.825 & 0.046 & 0.025 & & 246 & $1.3-503$ \\
\hline 15 & & 1.879 & 0.045 & 0.029 & & 232 & $1.1-289$ \\
\hline 16 & & 1.932 & 0.045 & 0.014 & & 58 & $1.4-257$ \\
\hline 17 & & 1.979 & 0.048 & 0.019 & & 193 & $1.7-93$ \\
\hline 18 & & 2.030 & 0.048 & 0.022 & & 195 & $2.0-88$ \\
\hline 19 & & 2.080 & 0.047 & 0.012 & & 53 & $3.8-221$ \\
\hline 20 & 7 & 2.129 & 0.047 & 0.003 & & 55 & $1.0-1309$ \\
\hline 21 & & 2.178 & 0.047 & 0.023 & & 211 & $2.3-255$ \\
\hline 22 & & 2.227 & 0.047 & 0.026 & & 240 & $2.0-245$ \\
\hline 23 & & 2.276 & 0.046 & 0.027 & & 263 & $1.6-198$ \\
\hline 24 & & 2.327 & 0.047 & 0.026 & & 268 & $1.5-140$ \\
\hline 25 & & 2.375 & 0.047 & 0.033 & & 329 & $1.0-83$ \\
\hline 26 & & 2.960 & 0.160 & 9.780 & 291 & TBD & 1.7 \\
\hline 27 & & 3.110 & 0.160 & 7.050 & 284 & $\mathrm{TBD}$ & 2.4 \\
\hline 28 & & 3.280 & 0.160 & 3.090 & 284 & TBD & 5.9 \\
\hline 29 & & 3.420 & 0.170 & 1.280 & 291 & TBD & 15.7 \\
\hline 30 & & 3.590 & 0.160 & 0.720 & 293 & TBD & 29.7 \\
\hline 31 & 20 & 3.740 & 0.150 & 0.470 & 293 & TBD & 47.5 \\
\hline 32 & 21 & 3.900 & 0.170 & 0.370 & 292 & TBD & 62.4 \\
\hline 33 & 23 & 4.050 & 0.160 & 0.300 & 289 & $\mathrm{TBD}$ & 78.2 \\
\hline 34 & & 4.210 & 0.160 & 0.810 & 257 & TBD & 23.8 \\
\hline 35 & & 4.360 & 0.150 & 1.740 & 234 & TBD & 9.5 \\
\hline 36 & 25 & 4.520 & 0.160 & 0.280 & 272 & TBD & 83.2 \\
\hline 37 & & 4.670 & 0.160 & 0.140 & 289 & TBD & 192.9 \\
\hline 38 & & 4.820 & 0.160 & 0.130 & 286 & TBD & 210.2 \\
\hline 39 & & 4.970 & 0.150 & 0.120 & 286 & TBD & 234.9 \\
\hline 40 & & 5.120 & 0.160 & 0.140 & 280 & TBD & 199.7 \\
\hline 41 & & 5.280 & 0.160 & 0.180 & 275 & TBD & 153.7 \\
\hline 42 & 29 & 8.600 & 0.440 & 0.140 & 292 & TBD & 363.2 \\
\hline 43 & 30 & 9.790 & 0.620 & 0.120 & 287 & TBD & 465.0 \\
\hline 44 & & 10.55 & 0.490 & 0.090 & 294 & TBD & 697.7 \\
\hline 45 & 31 & 11.02 & 0.540 & 0.100 & 294 & TBD & 654.7 \\
\hline 46 & 32 & 11.96 & 0.450 & 0.190 & 294 & TBD & 370.9 \\
\hline 47 & & 12.88 & 0.460 & 0.460 & 291 & TBD & 161.2 \\
\hline 48 & 33 & 13.23 & 0.470 & 0.490 & 283 & TBD & 147.0 \\
\hline 49 & 35 & 13.72 & 0.600 & 1.320 & 256 & $\mathrm{TBD}$ & 46.7 \\
\hline 50 & 36 & 14.17 & 0.420 & 2.000 & 229 & TBD & 25.5 \\
\hline
\end{tabular}

Page 8 


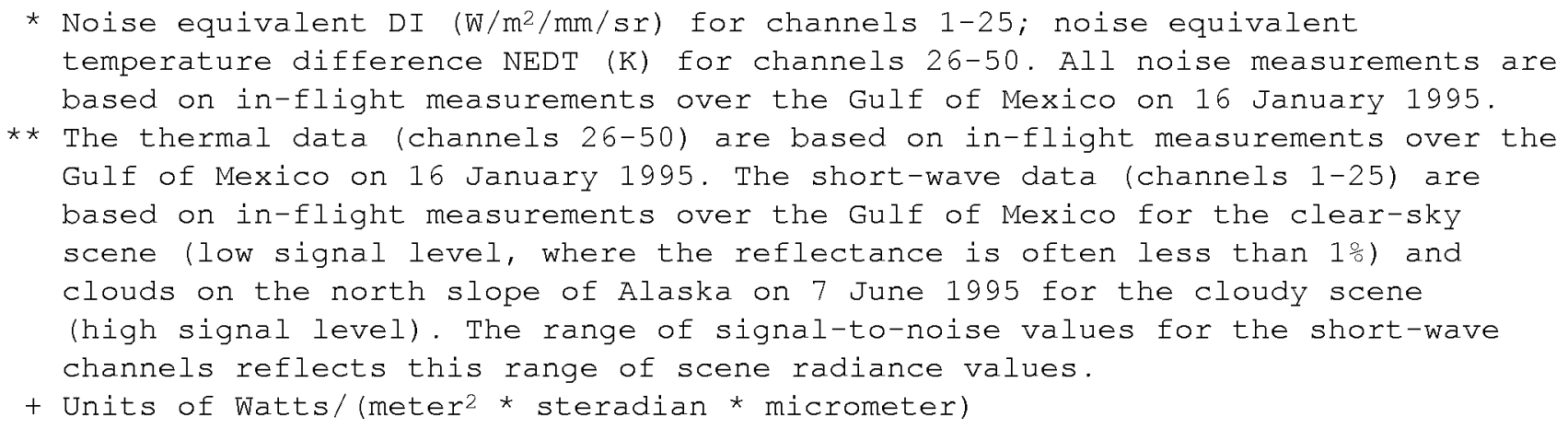

The wavelength range (in micrometers) of the MAS bands selected for the BOREAS/IFC-2 are:

$\begin{array}{cccc}\text { DATA CHANNEL } & \text { MAS BAND } & \text { Central Wavelength } & 50 \% \\ 01 & 01 & 0.547 & 0.043 \\ 02 & 02 & 0.664 & 0.055 \\ 03 & 04 & 0.745 & 0.040 \\ 04 & 05 & 0.786 & 0.040 \\ 05 & 06 & 0.834 & 0.042 \\ 06 & 07 & 0.875 & 0.041 \\ 07 & 09 & 0.945 & 0.043 \\ 08 & 10 & 1.623 & 0.057 \\ 09 & 20 & 2.142 & 0.047 \\ 10 & 32 & 3.900 & 0.150 \\ 11 & 45 & 11.002 & 0.448 \\ 12 & 46 & 12.032 & 0.447\end{array}$

\subsubsection{Tolerance}

Details of the shortwave calibration and temperature correction procedure are given by Arnold et al. (1994a, b).

\subsubsection{Frequency of Calibration}

A single set of calibration coefficients was used for all of the BOREAS flights.

\subsubsection{Other Calibration Information}

For a more detailed calibration description, the reader is directed to King, et al., 1995.

\section{Data Acquisition Methods}

As part of the BOREAS Staff Science data collection effort, the NASA ARC personnel collected and provided the 12-band MAS data to BOREAS for use in science investigations. The MAS was flown on NASA's C-130 aircraft during BOREAS (see the BOREAS Experiment Plan for flight pattern details and objectives). Maintenance and operation of the instrument are the responsibility of NASA ARC. 


\section{Observations}

\subsection{Data Notes}

data.

Flight summary reports and verbal records on video tapes are available for the BOREAS MAS

\subsection{Field Notes}

See the C-130 Flight Summary Report from the Aircraft Data Facility, NASA ARC.

\section{Data Description}

\subsection{Spatial Characteristics}

\subsubsection{Spatial Coverage}

Each of the MAS flight lines cover a portion of the BOREAS Southern Study Area (SSA) or Northern Study Area (NSA).

The North American Datum of 1983 (NAD83) corner coordinates of the SSA are:

$\begin{array}{lll} & \text { Latitude } & \text { Longitude } \\ & ------- & ------- \\ \text { Northwest } & 54.321 \mathrm{~N} & 106.228 \mathrm{~W} \\ \text { Northeast } & 54.225 \mathrm{~N} & 104.237 \mathrm{~W} \\ \text { Southwest } & 53.515 \mathrm{~N} & 106.321 \mathrm{~W} \\ \text { Southeast } & 53.420 \mathrm{~N} & 104.368 \mathrm{~W}\end{array}$

The NAD83 corner coordinates of the NSA are:

$\begin{array}{llc} & \text { Latitude } & \text { Longitude } \\ & ------- & ------- \\ \text { Northwest } & 56.249 \mathrm{~N} & 98.825 \mathrm{~W} \\ \text { Northeast } & 56.083 \mathrm{~N} & 97.234 \mathrm{~W} \\ \text { Southwest } & 55.542 \mathrm{~N} & 99.045 \mathrm{~W} \\ \text { Southeast } & 55.379 \mathrm{~N} & 97.489 \mathrm{~W}\end{array}$

\subsubsection{Spatial Coverage Map} Not available.

\subsubsection{Spatial Resolution}

At the nominal C-130 operating altitude of $8,000 \mathrm{~m}$, the MAS provided pixel resolutions of $20 \mathrm{~m}$ at nadir to $30 \mathrm{~m}$ at the scanning extremes.

\subsubsection{Projection}

The flight lines are stored in their raw spatial form with pixel resolutions varying from $20 \mathrm{~m}$ at nadir to $30 \mathrm{~m}$ at the scanning extremes. The provided files of relative $\mathrm{X}$ and $\mathrm{Y}$ coordinate indicate the relative positions of the pixels from the arbitrary origin. These relative $\mathrm{X}$ and $\mathrm{Y}$ coordinates were derived from the C-130 navigation data (see Section 9.3).

\subsubsection{Grid Description}

The provided files of relative $\mathrm{X}$ and $\mathrm{Y}$ coordinate indicate the relative positions of the pixels. These relative $\mathrm{X}$ and $\mathrm{Y}$ coordinates were derived from the $\mathrm{C}-130$ navigation data (see Section 9.3). 


\subsection{Temporal Characteristics}

\subsubsection{Temporal Coverage}

Overall the flight lines cover the period of 21-Jul-1994 to 08-Aug-1994.

\subsubsection{Temporal Coverage Map}

\begin{tabular}{|c|c|c|c|c|}
\hline & & Start & End & Number of \\
\hline Site & Date & Time & Time & Flight Lines \\
\hline------- & ----------- & -------- & -------- & ----- \\
\hline NSA & $08-\mathrm{AUG}-1994$ & $14: 31: 58$ & $15: 43: 08$ & 7 \\
\hline$S S A$ & $21-J U L-1994$ & $15: 46: 07$ & $17: 35: 35$ & 10 \\
\hline NSA-YJP & $04-\mathrm{AUG}-1994$ & $16: 47: 17$ & $17: 23: 00$ & 3 \\
\hline NSA-OBS & $04-\mathrm{AUG}-1994$ & $16: 23: 44$ & $16: 18: 02$ & 3 \\
\hline$S S A-9 Y A$ & 24-JUL-1994 & $17: 09: 44$ & $17-38: 34$ & 3 \\
\hline \multirow[t]{2}{*}{$S S A-F E N$} & 21-JUL-1994 & $30: 35: 48$ & $21: 15: 30$ & 3 \\
\hline & 24-JUL-1994 & $15: 58: 03$ & $16: 28: 30$ & 3 \\
\hline SSA-OJP & $21-J U L-1994$ & $19: 24: 26$ & $19: 53: 21$ & 3 \\
\hline SSA-OBS & 21-JUL-1994 & $18: 46: 32$ & $19: 16: 16$ & 3 \\
\hline$S S A-90 A$ & 21-JUL-1994 & $17: 46: 19$ & $18: 22: 03$ & 3 \\
\hline SSA-YJP & $21-J U L-1994$ & $20: 00: 06$ & $20: 26: 54$ & 3 \\
\hline
\end{tabular}

\subsubsection{Temporal Resolution}

The entire NSA and SSA were only imaged once in 1994. The dates and times for individual tower sites are shown in section 7.2.2.

\subsection{Data Characteristics}

\subsubsection{Parameter/Variable}

The main parameters contained in the image data files are:

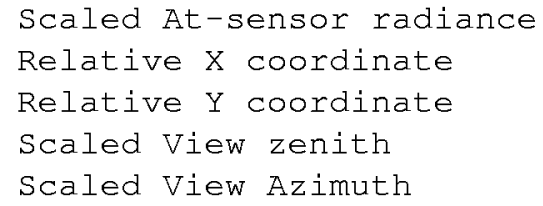

The parameters contained in the inventory listing file on the CD-ROM are:

$$
\text { Column Name }
$$

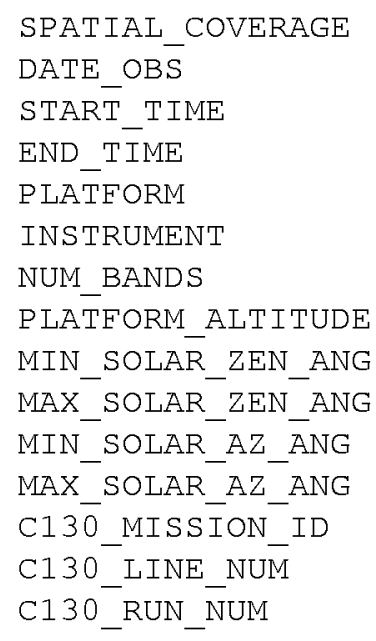




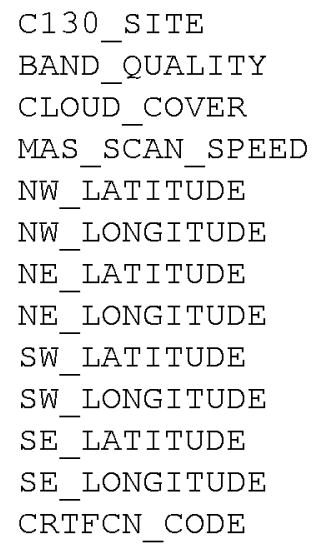

\subsubsection{Variable Description/Definition}

For the image data files:

\section{Scaled At-sensor Radiance}

The derived radiant energy incident on the sensor aperture at the time of data collection in the specific MAS wavelength regions.

\section{Relative X Coordinate}

The $\mathrm{X}$ coordinate of the center of the image pixel in relation to the arbitrarily selected origin. The trend of the X coordinates of the pixels is dependent on the direction of flight of the aircraft. The X, Y coordinate system, starts with the nadir pixel location of image line 1 for all flight lines positioned near the origin $(0,0)$ and progresses based on the direction of flight. The flight direction refers to the angle of the flight path relative to magnetic North with North as 0 or 360 degrees, East as 90 , South as 180 , and West as 270 degrees. For example, the $X$ coordinates for an idealized flight line in the direction of 180 degrees (South) would be increasingly positive to the left of the flight line and increasingly negative to the right of the flight line with the $\mathrm{X}$ coordinate for the nadir pixel being approximately 0 (zero).

\section{Relative Y Coordinate}

The Y coordinate of the center of the image pixel in relation to the arbitrarily selected origin. The trend of the $\mathrm{Y}$ coordinates of the pixels is dependent on the direction of flight of the aircraft. The $\mathrm{X}, \mathrm{Y}$ coordinate system, starts with the nadir pixel location of image line 1 for all flight lines positioned near the origin $(0,0)$ and progresses based on the direction of flight. The flight direction refers to the angle of the flight path relative to magnetic North with North as 0 or 360 degrees, East as 90, South as 180 , and West as 270 degrees. For example, the Y coordinates for an idealized flight line in the direction of 90 degrees (East) would be increasingly positive to the left of the flight line and increasingly negative to the right of the flight line with the $\mathrm{Y}$ coordinate for the nadir pixel being approximately 0 (zero).

\section{Scaled View Zenith}

The scaled value of the target-centered view zenith angle (complement of elevation angle). The view zenith indicates the zenith angle at which the radiant energy was traveling when detected by the sensor. The view zenith angle increases from 0 (straight up) to 90 degrees at the horizon.

\section{Scaled View Azimuth}

The scaled value of the target-centered view azimuth angle. The view azimuth angle indicates the direction in which the radiant energy was traveling when detected by the sensor. The view azimuth angle increases from 0 to 360 degrees with North as 0 or 360 degrees, East as 90, South as 180, and West as 270 degrees. 


\section{The descriptions of the parameters contained in the inventory listing file on the CD-ROM are:}

\begin{tabular}{|c|c|}
\hline Column Name & Description \\
\hline SPATIAL_COVERAGE & $\begin{array}{l}\text { The general term used to denote the spatial area } \\
\text { over which the data were collected. }\end{array}$ \\
\hline DATE_OBS & The date on which the data were collected. \\
\hline START_TIME & $\begin{array}{l}\text { The starting Greenwich Mean Time (GMT) for the } \\
\text { data collected. }\end{array}$ \\
\hline END_TIME & $\begin{array}{l}\text { The ending Greenwich Mean Time (GMT) for the } \\
\text { data collected. }\end{array}$ \\
\hline PLATFORM & $\begin{array}{l}\text { The object (e.g., satellite, aircraft, tower, } \\
\text { person) that supported the instrument. }\end{array}$ \\
\hline INSTRUMENT & $\begin{array}{l}\text { The name of the device used to make the } \\
\text { measurements. }\end{array}$ \\
\hline NUM_BANDS & The number of spectral bands in the data. \\
\hline PLATTFORM_ALTITUDE & $\begin{array}{l}\text { The nominal altitude of the data collection } \\
\text { platform above the target. }\end{array}$ \\
\hline MIN_SOLAR_ZEN_ANG & $\begin{array}{l}\text { The minimum angle from the surface normal } \\
\text { (straight up) to the sun during the data } \\
\text { collection. }\end{array}$ \\
\hline MAX_SOLAR_ZEN_ANG & $\begin{array}{l}\text { The maximum angle from the surface normal } \\
\text { (straight up) to the sun during the data } \\
\text { collection. }\end{array}$ \\
\hline MIN_SOLAR_AZ_ANG & $\begin{array}{l}\text { The minimum azimuthal direction of the sun } \\
\text { during data collection expressed in clockwise } \\
\text { increments from North. }\end{array}$ \\
\hline MAX_SOLAR_AZ_ANG & $\begin{array}{l}\text { The maximum azimuthal direction of the sun } \\
\text { during data collection expressed in clockwise } \\
\text { increments from North. }\end{array}$ \\
\hline C130_MISSION_ID & $\begin{array}{l}\text { The mission identifier assigned to the C-130 } \\
\text { mission in the form of YY-DDD-FF where YY is the } \\
\text { last two digits of the fiscal year, DDD is the } \\
\text { deployment number for "official" C-130 missions } \\
\text { and is day of year for non-"official" C-130 } \\
\text { missions (i.e." no site coverage), and FF is the } \\
\text { flight number within the given deployment (00 is } \\
\text { given for non-"official" C-130 missions). An } \\
\text { example would be 94-006-04. }\end{array}$ \\
\hline C130_LINE_NUM & $\begin{array}{l}\text { The number of the C-130 line in its flights over } \\
\text { the BOREAs area as given in the flight logs. } \\
\text { zero values are given for non-"official" C-130 } \\
\text { missions and for data between C-130 sites or } \\
\text { lines. }\end{array}$ \\
\hline C130_RUN_NUM & $\begin{array}{l}\text { The number of the C-130 run in its flights over } \\
\text { the BOREAs area as given in the flight logs. } \\
\text { zero value is given for non-"official" C-130 } \\
\text { missions and data between C-130 sites, lines or } \\
\text { runs. }\end{array}$ \\
\hline C130_SITE & $\begin{array}{l}\text { The C-130 site designator as given in the flight } \\
\text { logs. PRE is used for data taken from the } \\
\text { airport to the first "official" C-130 site, BTW is } \\
\text { used for data taken between two "official" C-130 } \\
\text { sites, DSC is used for data taken after the last }\end{array}$ \\
\hline
\end{tabular}




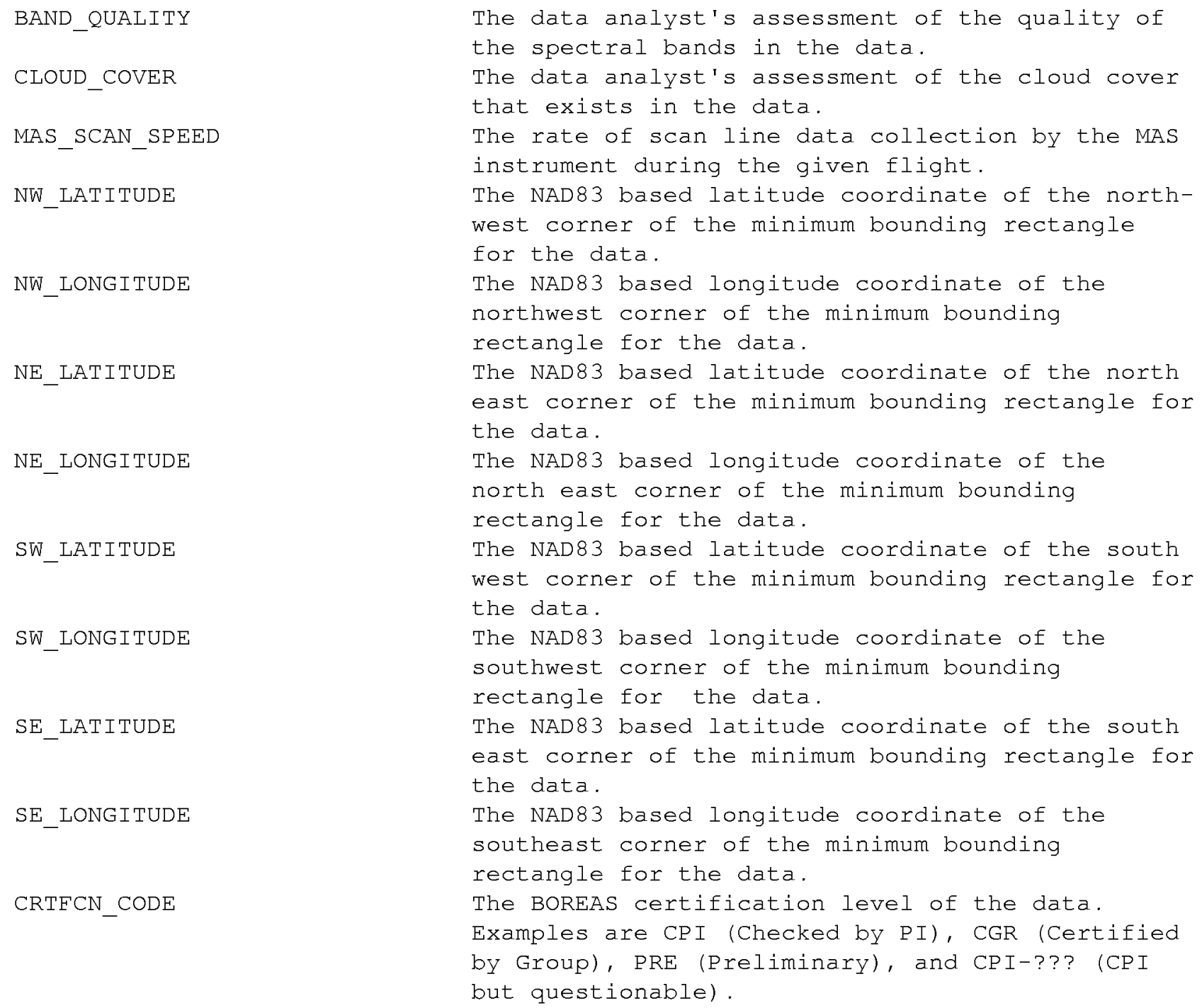

\subsubsection{Unit of Measurement}

For the image data files:

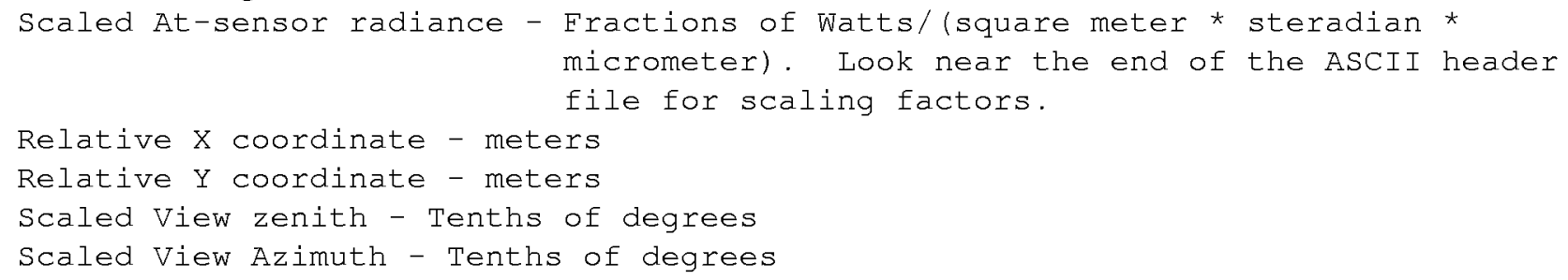

\section{Page 14}


The measurement units for the parameters contained in the inventory listing file on the CD-ROM are:

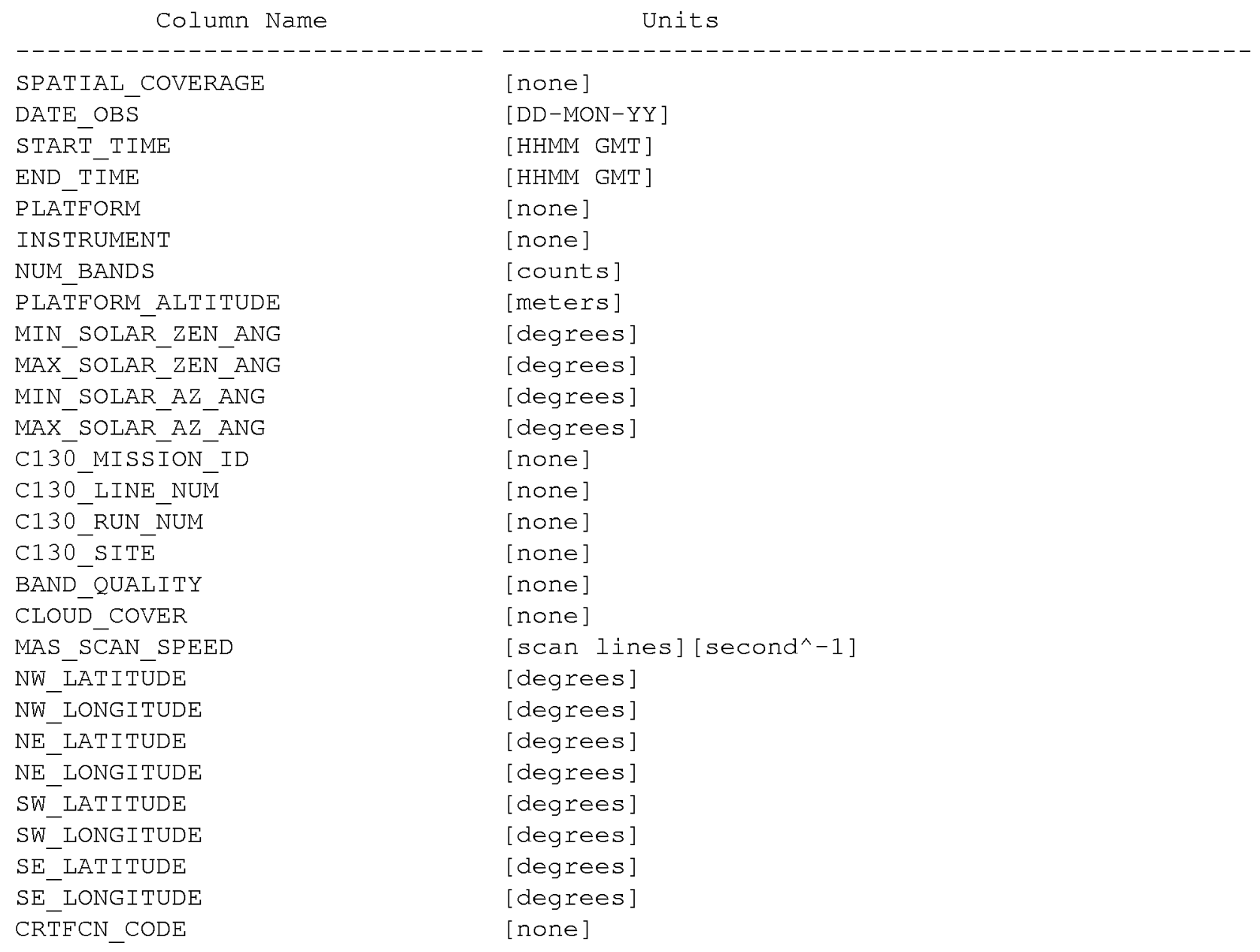

\subsubsection{Data Source}

The values stored in the listed parameters were extracted from the level-1b MAS HDF files provided to BOREAS by MAS processing personnel. The scaled at-sensor radiance and view angle values are the result of calibration and processing of the raw MAS data by MAS personnel. The relative $\mathrm{X}$ and $\mathrm{Y}$ coordinates were derived in a joint effort between BORIS and MAS personnel using developed software. The sources of the parameter values contained in the inventory listing file on the CD-ROM are:

\begin{tabular}{|c|c|}
\hline Column Name & Data Source \\
\hline SPATIAL_COVERAGE & $\begin{array}{l}\text { [Determined from latitude and longitude } \\
\text { information provided in the NASA Ames flight } \\
\text { summary reports and navigation data files] }\end{array}$ \\
\hline DATE_OBS & [Software extracted from MAS HDF files] \\
\hline START_TIME & [Software extracted from MAS HDF files] \\
\hline END_TIME & [Software extracted from MAS HDF files] \\
\hline PLAT̄EORM & [Data base constant] \\
\hline INSTRUMENT & [Data base constant] \\
\hline NUM_BANDS & [Data base constant] \\
\hline PLATFORM_ALTITUDE & $\begin{array}{l}\text { [Determined from information provided in the NASA } \\
\text { Ames flight summary reports] }\end{array}$ \\
\hline
\end{tabular}




\author{
MIN_SOLAR_ZEN_ANG \\ MAX_SOLAR_ZEN_ANG \\ MIN_SOLAR_AZ_ANG \\ MAX_SOLAR_AZ_ANG \\ C130_MISSION_ID \\ C130_LINE_NUM \\ C130_RUN_NUM \\ C130_SITE \\ BAND QUALITY \\ CLOUD_COVER \\ MAS SCAN SPEED \\ NW_LATITŪDE
}

NW_LONGITUDE

NE_LATITUDE

NE_LONGITUDE

SW_LATITUDE

SW_LONGITUDE

SE_LATITUDE

SE_LONGITUDE

CRTFCN_CODE
[Calculated with software from latitude and longitude and time information]

[Calculated with software from latitude and longitude and time information]

[Calculated with software from latitude and longitude and time information]

[Calculated with software from latitude and longitude and time information]

[Taken from the delivered tape label and the NASA Ames Flight Summary Reports]

[Taken from the delivered tape label and the NASA Ames Flight Summary Reports]

[Taken from the delivered tape label and the NASA

Ames Flight Summary Reports]

[Taken from the delivered tape label and the NASA

Ames Flight Summary Reports]

[Constant software parameter value]

[Constant software parameter value]

[Software extracted from MAS HDF files]

[Calculated with software from the C-130 altitude and heading, starting and ending flight line

latitude and longitude, and the static MAS scan angle information]

[Calculated with software from the C-130 altitude and heading, starting and ending flight line latitude and longitude, and the static MAS scan angle information]

[Calculated with software from the C-130 altitude and heading, starting and ending flight line

latitude and longitude, and the static MAS scan angle information]

[Calculated with software from the C-130 altitude and heading, starting and ending flight line

latitude and longitude, and the static MAS scan angle information]

[Calculated with software from the C-130 altitude and heading, starting and ending flight line latitude and longitude, and the static MAS scan angle information]

[Calculated with software from the C-130 altitude and heading, starting and ending flight line latitude and longitude, and the static MAS scan angle information]

[Calculated with software from the C-130 altitude and heading, starting and ending flight line

latitude and longitude, and the static MAS scan angle information]

[Calculated with software from the C-130 altitude and heading, starting and ending flight line

latitude and longitude, and the static MAS scan angle information]

[Constant data base value]

\section{Page 16}




\subsubsection{Data Range}

The range of values for the image data files are:

\section{Scaled At-sensor Radiance}

Dependent on the particular MAS band of interest due to the wavelength region covered and the scaling factor listed near the end of the ASCII header file.

\section{Relative X Coordinate}

Dependent on the direction of flight with an absolute minimum of $-2,147,483,648$ and absolute maximum of 2,147,483,647.

\section{Relative Y Coordinate}

Dependent on the direction of flight with an absolute minimum of -2,147,483,648 and absolute maximum of 2,147,483,647.

\section{Scaled View Zenith}

Minimum - 0

Maximum - 900

\section{Scaled View Azimuth}

Minimum - 0

Maximum - 3599

The following table gives information about the parameter values found in the inventory table on the CD-ROM.

\begin{tabular}{|c|c|c|c|c|c|c|}
\hline Column Name & $\begin{array}{l}\text { Minimum } \\
\text { Data } \\
\text { Value }\end{array}$ & $\begin{array}{l}\text { Maximum } \\
\text { Data } \\
\text { Value }\end{array}$ & $\begin{array}{l}\text { Missng } \\
\text { Data } \\
\text { Value }\end{array}$ & $\begin{array}{l}\text { Unrel } \\
\text { Data } \\
\text { Value }\end{array}$ & $\begin{array}{l}\text { Below } \\
\text { Detect } \\
\text { Limit }\end{array}$ & $\begin{array}{l}\text { Data } \\
\text { Not } \\
\text { Cllctd }\end{array}$ \\
\hline \multicolumn{7}{|c|}{ 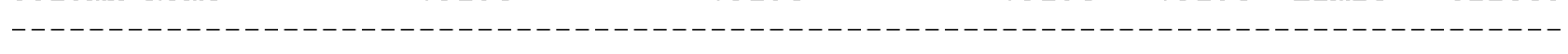 } \\
\hline SPATIAL_COVERAGE & $\mathrm{N} / \mathrm{A}$ & $\mathrm{N} / \mathrm{A}$ & None & None & None & None \\
\hline DATE_OBS & $21-J U L-94$ & $08-A U G-94$ & None & None & None & None \\
\hline START_TIME & 1431 & 2110 & None & None & None & None \\
\hline END_TIME & 1435 & 2115 & None & None & None & None \\
\hline PLAT̄FORM & $C-130$ & $C-130$ & None & None & None & None \\
\hline INSTRUMENT & $\mathrm{N} / \mathrm{A}$ & $\mathrm{N} / \mathrm{A}$ & None & None & None & None \\
\hline NUM_BANDS & 12 & 12 & None & None & None & None \\
\hline PLATFORM_ALTITUDE & 5369 & 7962 & None & None & None & None \\
\hline MIN_SOLAR_ZEN_ANG & 33.5 & 60.8 & None & None & None & None \\
\hline MAX_SOLAR_ZEN_ANG & 33.5 & 60.8 & None & None & None & None \\
\hline MIN_SOLAR_AZ_ANG & 104.7 & 228.4 & None & None & None & None \\
\hline MAX_SOLAR_AZ_ANG & 104.7 & 228.4 & None & None & None & None \\
\hline C130_MISSION_ID & $94-007-02$ & $94-007-07$ & None & None & None & None \\
\hline C130_LINE_NUM & 1 & 703 & None & None & None & None \\
\hline C130_RUN_NUM & 1 & 2 & None & None & None & None \\
\hline C130_SITE & 429 & 432 & None & None & None & None \\
\hline BAND_QUALITY & $\mathrm{N} / \mathrm{A}$ & $\mathrm{N} / \mathrm{A}$ & None & None & None & None \\
\hline CLOUD_COVER & $\mathrm{N} / \mathrm{A}$ & $\mathrm{N} / \mathrm{A}$ & None & None & None & None \\
\hline MAS_SCAN_SPEED & 6.25 & 6.25 & None & None & None & None \\
\hline NW_LATITŪDE & 53.67695 & 56.08457 & None & None & None & None \\
\hline NW_LONGITUDE & -106.49118 & -98.43622 & None & None & None & None \\
\hline NE_LATITUDE & 53.65457 & 56.02245 & None & None & None & None \\
\hline NE_LONGITUDE & -106.04228 & -98.01404 & None & None & None & None \\
\hline SW_LATITUDE & 53.45052 & 55.92475 & None & None & None & None \\
\hline SW_LONGITUDE & -106.50745 & -98.48084 & None & None & None & None \\
\hline
\end{tabular}




\begin{tabular}{|c|c|}
\hline SE_LATITUDE & 55.88116 \\
\hline SE_LONGITUDE & -106.06016 \\
\hline CRTFCN_CODE & $\mathrm{CPI}-\mathrm{PRE}$ \\
\hline inimum Data Value & -- The minimum value found in the column. \\
\hline Maximum Data Value & -- The maximum value found in the column. \\
\hline Missng Data Value & $\begin{array}{l}\text {-- The value that indicates missing data. This is used to } \\
\text { indicate that an attempt was made to determine the } \\
\text { parameter value, but the attempt was unsuccessful. }\end{array}$ \\
\hline Unrel Data Value & $\begin{array}{l}\text {-- The value that indicates unreliable data. This is used } \\
\text { to indicate an attempt was made to determine the } \\
\text { parameter value, but the value was deemed to be } \\
\text { unreliable by the analysis personnel. }\end{array}$ \\
\hline Below Detect Limit & $\begin{array}{l}\text {-- The value that indicates parameter values below the } \\
\text { instruments detection limits. This is used to } \\
\text { indicate that an attempt was made to determine the } \\
\text { parameter value, but the analysis personnel determined } \\
\text { that the parameter value was below the detection } \\
\text { limit of the instrumentation. }\end{array}$ \\
\hline Data Not Cllctd & $\begin{array}{l}\text {-- This value indicates that no attempt was made to } \\
\text { determine the parameter value. This usually } \\
\text { indicates that BoRIs combined several similar but } \\
\text { not identical data sets into the same data base table } \\
\text { but this particular science team did not } \\
\text { measure that parameter. }\end{array}$ \\
\hline Blank -- Indicates & that blank spaces are used to denote that type of value. \\
\hline -- Indicates & that the value is not applicable to the respective column. \\
\hline -- Indicates & that no values of that sort were found in the column. \\
\hline
\end{tabular}

\subsection{Sample Data Record}

A sample data record for the level-1b MAS image data files is not available here. The following are wrapped versions of the first few records from the level-1b MAS inventory table on the CD-ROM:

SPATIAL_COVERAGE,DATE_OBS, START_TIME, END_TIME, PLATFORM, INSTRUMENT, NUM_BANDS, PLATFORM_ALTITUDE,MIN_SOLAR_ZEN_ANG, MAX_SOLAR_ZEN_ANG, MIN_SOLAR_AZ_ANG,

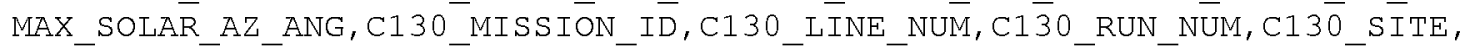
BAND_QUALITY,CLOUD_COVER, MAS_SCAN_SPEED,NW_LATITUDE, NW_LONGITUDE,NE_LATITUDE, NE_LONGITUDE, SW_LATITUDE, SW_LONGITUDE, SE_LĀTITUDE, SE_LONNGITUDE, CRTFCN_CODE

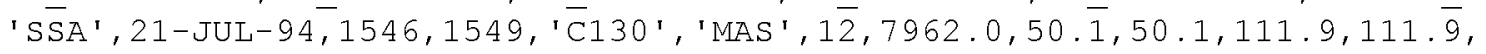
'94-007-02',1,1,'430','Fair: some noise in IR channels', 'NOT ASSESSED', $6.25,54.09045,-104.73796,54.06945,-104.35302,53.94723,-104.7599,53.9263$, $-104.3763,{ }^{\prime} \mathrm{CPI}-\mathrm{PRE}$ '

'SSA', 21-JUL-94,1555,1600, 'C130', 'MAS', 12,7847.0,48.7,48.7,114.7,114.7, ' 94-007-02',2,1,' 430',' 'Fair: some noise in IR channels', 'NOT ASSESSED', $6.25,54.1104,-104.95096,54.07979,-104.37902,53.91345,-104.98007,53.88298$, $-104.41086,{ }^{\prime} \mathrm{CPI}-\mathrm{PRE}$ '

\section{Page 18}




\section{Data Organization}

\subsection{Data Granularity}

The smallest unit of data for level-1b MAS images is a single image - one of the 16 image bands of a MAS scene collected over the BOREAS SSA and NSA. Each scene represents imaging performed over a portion of a sight during one flight line. A scene is made up of 17 sequential 8-mm tape files described below.

\subsection{Data Format(s)}

The CD-ROM inventory listing file consists of numerical and character fields of varying length separated by commas. The character fields are enclosed with single apostrophe marks. There are no spaces between the fields.

One level-1b MAS image product consists of 17 files in the following order:

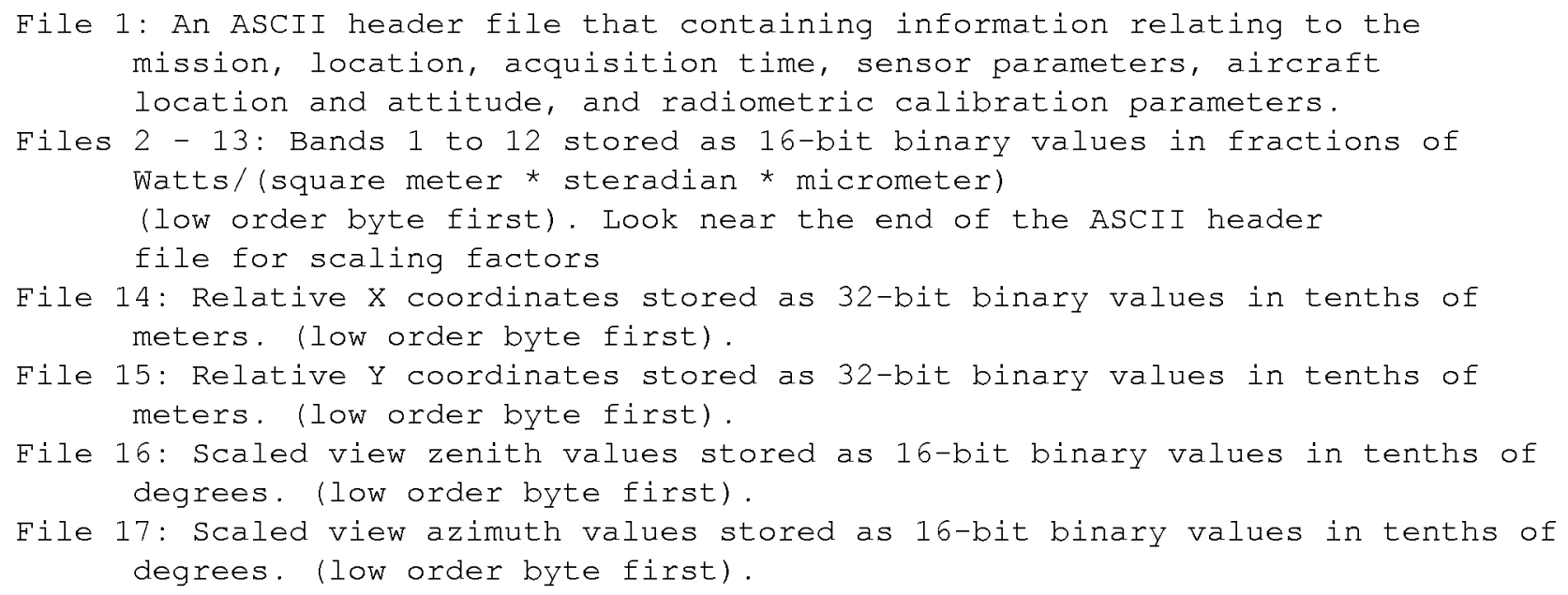

The second scene on the tape occupies tape files 18 - 34. The third scene on the tape occupies tape files 35 - 47 and so on.

The geographic orientation of each scene depends on the direction of the aircraft line of flight. Pixels and lines progress left to right, and top to bottom so that pixel $n$, line $n$ is in the lower right-hand corner of each scene.

All scene files exist on tape as a variable number of fixed length records. ASCII header files are 80 bytes in length. All binary files associated together for a given flight contain the same number of records. The number of binary records in a flight varies depending on the length of that flight line. Each binary data record in all flights represents 716 image pixels and are padded to an even multiple of 512. Therefore, the image and view angle file records contain $716 * 2+104$ bytes of padding $=1536$ bytes and the relative $X$ and $Y$ coordinate files contain $716 * 4+208$ bytes of padding $=3072$ bytes. 


\section{Data Manipulations}

\subsection{Formulae}

\subsubsection{Derivation Techniques and Algorithms}

Derivation of the relative $\mathrm{X}$ and $\mathrm{Y}$ coordinates starts with determining the relative positions of the nadir pixel in each image line. The nadir pixel coordinates are defined to proceed relative to an arbitrary starting $\mathrm{X}, \mathrm{Y}$ location. Nadir $\mathrm{X}, \mathrm{Y}$ coordinates are derived as a function of the following parameters:

- Instantaneous Velocities $\mathrm{X}, \mathrm{Y}$, and $\mathrm{Z}$ from the $\mathrm{C}-130$ navigation data.

- Tracking (actual direction aircraft is pointing) values derived as a function of true heading and drift. To arrive upon nadir pixel tracking, the $1-\mathrm{Hz}$ drift values and $30-\mathrm{Hz}$ true heading values are interpolated to nadir pixel values. Nadir pixel drift is added to the nadir true heading values to obtain nadir pixel tracking values. Note that drift may be a positive or negative value.

The calculations used to derive relative $\mathrm{X}$ and $\mathrm{Y}$ coordinates of the nadir pixels are:

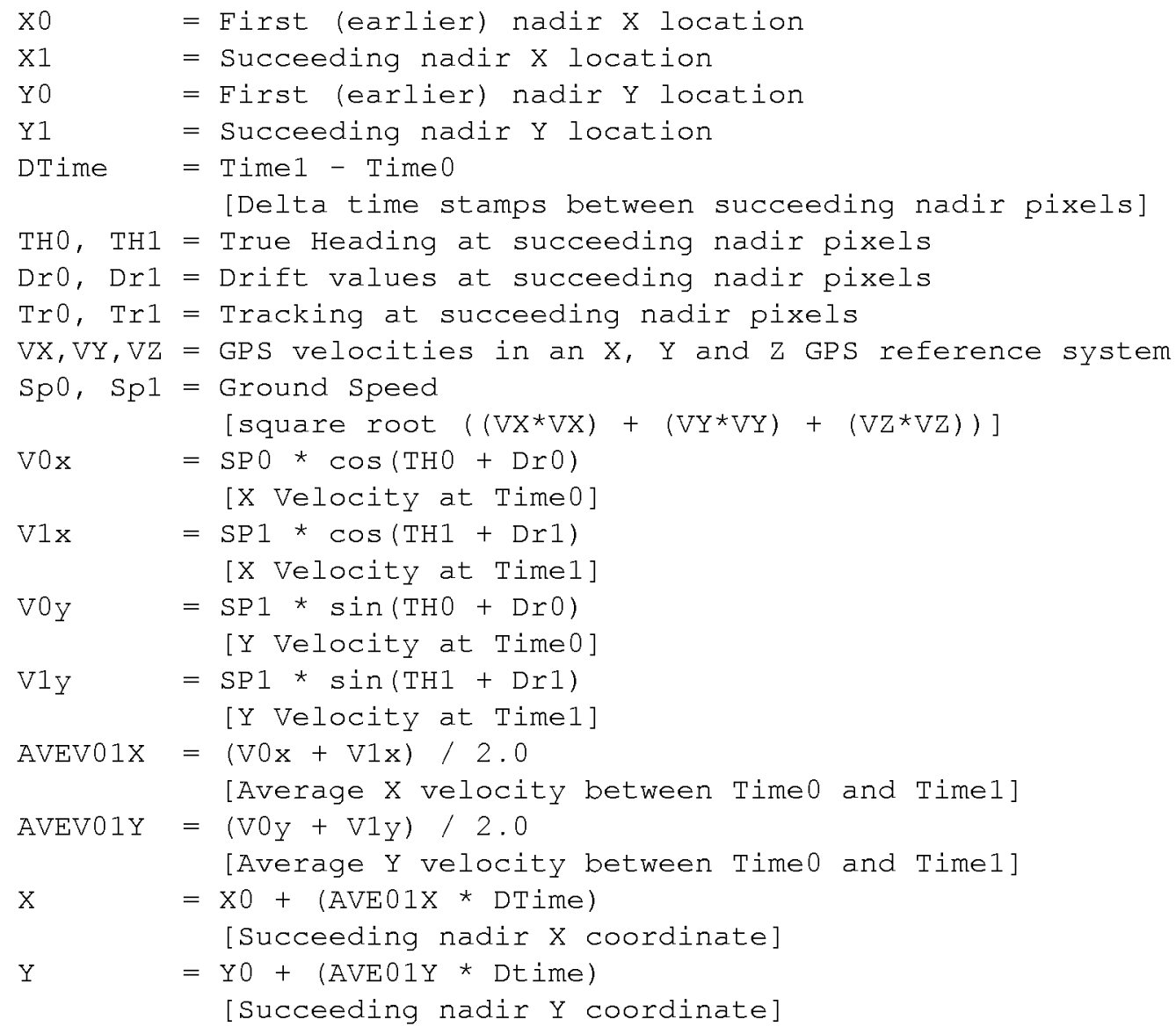

Once the position of the aircraft at the center pixel time is known, what remains to be determined is the center pixel position on the ground and along the scan line on each side. The latter is determined by dividing the ScanAngle by the number or pixels, e.g.:

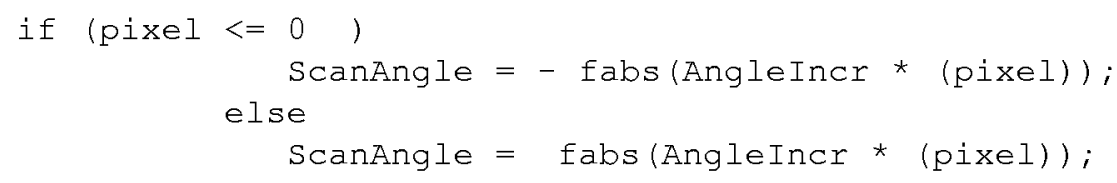


The Center Pixel Position on the ground is determined by the trigonometry of the sensor's position which varies by pitch, altitude, heading and scan angle as the MAS sensor is roll-compensated:

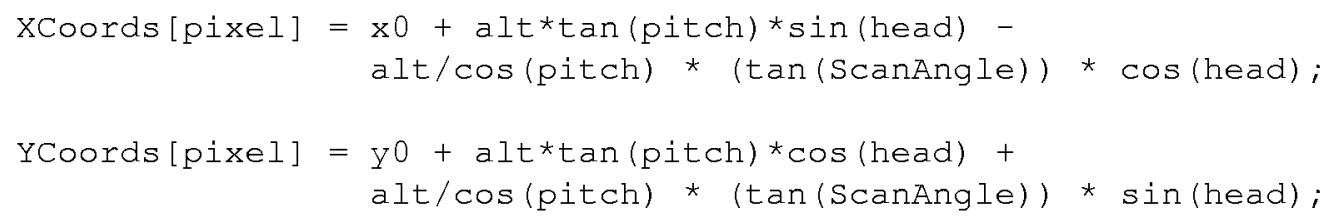

\subsection{Data Processing Sequence}

\subsubsection{Processing Steps}

BORIS staff creates the level-1b MAS image products from HDF files. The input HDF file is created by combining MAS image data with aircraft navigation data in an iterative procedure as follows:

- $\quad$ BORIS staff extracts start and end flight line times from the level-0 C-130 aircraft navigation data associated with the flight.

- The start and end times for the flight line are used by BORIS staff to extract the relevant aircraft navigation data to determine nadir pixel times.

- BORIS staff processes/linearly interpolates the extracted navigation parameters such as roll, pitch, heading, drift, and acceleration for the nadir pixel time.

- The nadir location parameters (roll, pitch, radar altitude, X and Y grid coordinates) are plotted to perform visual review of the data for anomalous values.

- Nadir pixel navigation parameter values are then combined with MAS spectral data by MAS processing staff to create an HDF image product consisting of MAS spectral data and ancillary information for each flight line run.

- $\quad$ All HDF files are written to 8-mm tape and logged in the BORIS data base.

- $\quad$ Each MAS HDF file is converted to the BORIS BSQ 8-mm tape product.

- $\quad$ The 17 files, as described above, for each unique flight, are written to tape, in BORIS level-1b BSQ format, for distribution.

- $\quad$ The BORIS format MAS tapes are then logged into the BORIS data base.

\subsubsection{Processing Changes}

None.

\subsection{Calculations}

\subsubsection{Special Corrections/Adjustments}

See Section 9.1.1.

\subsubsection{Calculated Variables}

See Section 9.1.1.

\subsection{Graphs and Plots}

None. 


\section{Errors}

\subsection{Sources of Error}

Errors could arise in the acquired imagery due to location accuracy, distortion of lengths, anisomorphism, instrument's local coherence, and multispectral registerability. Other errors could arise from inherent radiometric imperfections of the sensors.

Whatever the processing level, the geometric quality of the image depends on the accuracy of the viewing geometry.

Spectral errors could arise due to image-wide signal-to-noise ratio, saturation, cross-talk, spikes, and response normalization due to change in gain.

\subsection{Quality Assessment}

\subsubsection{Data Validation by Source}

None.

\subsubsection{Confidence Level/Accuracy Judgment}

One set of calibration coefficients was used throughout the BOREAS project rather than recalculating for each flight. Errors are usually $+/-5 \%$ when recalculated for each flight.

\subsubsection{Measurement Error for Parameters}

None given.

\subsubsection{Additional Quality Assessments}

None.

\subsubsection{Data Verification by Data Center}

BORIS staff calculated the length of the sides of the images from the $\mathrm{X}$ and $\mathrm{Y}$ coordinate files of the MAS scenes and compared with data from the flight summary report: An image with 1,416 scan lines at $6.25 \mathrm{scan} / \mathrm{sec}$ should have a flight time of $226 \mathrm{secs}$. A flight time of $226 \mathrm{secs}$ at $200 \mathrm{knots}$ should yield an image that is $23 \mathrm{~km}$ long. An instrument with a TFOV of $85.92^{\circ}$ at an altitude of 8,000 $\mathrm{m}$ should produce an image with a ground width of $7.5 \mathrm{~km}$.

BORIS staff visually compared some of the MAS images that were geometrically (not geographically) corrected with the relative X and Y coordinates to registered Landsat Thematic Mapper (TM) images. The geometry and positioning of the features in the MAS images matched well with those in the Landsat TM scene.

\section{Notes}

\subsection{Limitations of the Data} None.

\subsection{Known Problems with the Data}

None.

\subsection{Usage Guidance} None.

\subsection{Other Relevant Information None.}




\section{Application of the Data Set}

These data could be used as a first step to creating surface energy and reflectance maps of the imaged areas. They could also be used in comparison studies with the Landsat images acquired over the areas. Lastly, they could be compared with actual MODIS data after it is available later in 1999.

\section{Future Modifications and Plans}

None given.

\section{Software}

\subsection{Software Description}

BORIS personnel developed software and command procedures to:

- $\quad$ Unpack and subset the level-0 C-130 navigation data.

- Perform linear interpolation of the level-0 C-130 navigation parameters.

- Convert the HDF data files received from MAS personnel to the BORIS BSQ 8-mm tape product.

- Write the 17 files for each unique flight to tape for distribution.

- Extract header information from level-1b BSQ images on tape.

- $\quad$ Log the BSQ format MAS tapes into the BORIS data base.

The software is written in the C language and is operational on VAX 6410 and MicroVAX 3100 systems at GSFC. The primary dependencies in the software are the tape I/O library and the Oracle data base utility routines.

The details of the software used by MAS personnel to derive the HDF level-1b products are currently unknown.

\subsection{Software Access}

All of the described BORIS software is available upon request. BORIS staff would appreciate knowing of any problems discovered with the software, but cannot promise to fix them.

\section{Data Access}

The level-1b MAS images are available from the Earth Observing System Data and Information System (EOSDIS) Oak Ridge National Laboratory (ORNL) Distributed Active Archive Center (DAAC).

\subsection{Contact Information}

For BOREAS data and documentation please contact:

ORNL DAAC User Services

Oak Ridge National Laboratory

P.O. Box 2008 MS-6407

Oak Ridge, TN 37831-6407

Phone: (423) 241-3952

Fax: (423) 574-4665

E-mail: ornldaac@ornl.gov or orn1@eos.nasa.gov 


\subsection{Data Center Identification}

Earth Observing System Data and Information System (EOSDIS) Oak Ridge National Laboratory (ORNL) Distributed Active Archive Center (DAAC) for Biogeochemical Dynamics

http://www-eosdis.ornl.gov/.

\subsection{Procedures for Obtaining Data}

Users may obtain data directly through the ORNL DAAC online search and order system [http://www-eosdis.ornl.gov/] and the anonymous FTP site [ftp://www-eosdis.ornl.gov/data/] or by contacting User Services by electronic mail, telephone, fax, letter, or personal visit using the contact information in Section 15.1.

\subsection{Data Center Status/Plans}

The ORNL DAAC is the primary source for BOREAS field measurement, image, GIS, and hardcopy data products. The BOREAS CD-ROM and data referenced or listed in inventories on the CD-ROM are available from the ORNL DAAC.

\section{Output Products and Availability}

\subsection{Tape Products}

The BOREAS level-1b MAS data can be made available on 8-mm, Digital Archive Tape (DAT), or 9-track tapes at 1600 or 6250 Bytes Per Inch (BPI).

\subsection{Film Products}

Color aerial photographs and video records were made during data collection. The video record includes aircraft crew cabin intercom conversations and an audible tone that was initiated each time the sensor was triggered. The BOREAS data base contains an inventory of available BOREAS aircraft flight documentation, such as flight logs, video tapes, and photographs.

\subsection{Other Products}

Although the inventory is contained on the BOREAS CD-ROM set, the actual level-1b MAS images are not. See Section 15 for information about how to obtain the data.

\section{References}

\subsection{Platform/Sensor/Instrument/Data Processing Documentation} Arnold, G.T., M. Fitzgerald, P.S. Grant, and M.D. King. 1994a. MODIS Airborne Simulator Visible and Near-Infrared Calibration - 1992 ASTEX Field Experiment: Calibration Version - ASTEX King 1.0. NASA Technical Memorandum 104599, 19 pp.

Arnold, G.T., M. Fitzgerald, P.S. Grant, and M.D. King. 1994b. MODIS Airborne Simulator Visible and Near-Infrared Calibration - 1991 FIRE-Cirrus Field Experiment: Calibration Version - FIRE King 1.1. NASA Technical Memorandum 104600, 23 pp.

Gumley, L.E., P.A. Hubanks, and E.J. Masuoka. 1994. MODIS Airborne Simulator Level 1B data user's guide. NASA Technical Memorandum 104594 Vol. 3, NASA Goddard Space Flight Center, Greenbelt MD.

\subsection{Journal Articles and Study Reports}

Anderson, G.P. and J.H. Chetwynd. 1992. FASCOD3P User's Guide, Phillips Laboratory, Hanscom AFB. 
Ardanuy, P.E., D. Han, and V.V. Salomonson. 1991. The Moderate Resolution Imaging Spectrometer (MODIS) science and data system requirements. IEEE Trans. Geosci. Remote Sens., 29, 75-88.

Bromba, M.U.A. and H. Ziegler. 1981. Digital filter for computationally efficient smoothing of noisy spectra. Anal. Chem., 53, 1299-1302.

Clough, S.A., F.X. Kneizys, L.S. Rothman, and W.O. Gallery. 1981. Atmospheric spectral transmittance and radiance: FASCOD1B. SPIE, 277, 152-166.

Gao, B.C., A.F.H. Goetz, and W.J. Wiscombe. 1993. Cirrus cloud detection from airborne imaging spectrometer data using the $1.38 \mathrm{~mm}$ water vapor band. Geophys. Res. Lett., 20, 301-304.

Gumley, L.E. and M.D. King. 1995. Remote sensing of flooding in the US upper Midwest during the summer of 1993. Bull. Amer. Meteor. Soc., 76, 933-943.

Huh, O.K., C.C. Moeller, W.P. Menzel, L.J. Rouse, Jr., and H.H. Roberts. 1995. Remote sensing of turbid coastal and estuarine water: A method of multispectral water-type analysis. Submitted to J. Coastal Res.

Jedlovec, G.J., K.B. Batson, R.J. Atkinson, C.C. Moeller, W.P. Menzel, and M.W. James. 1989. Improved Capabilities of the Multispectral Atmospheric Mapping Sensor (MAMS). NASA Technical Memorandum 100352, Marshall Space Flight Center, Huntsville, AL, 71 pp.

Kaufman, Y.J. and B.C. Gao. 1992. Remote sensing of water vapor in the near IR from EOS/MODIS. IEEE Trans. Geosci. Remote Sens., 30, 871-884.

King, M.D., D.D. Herring, and D.J. Diner. 1995. The Earth Observing System (EOS): A space-based program for assessing mankind's impact on the global environment. Opt. Photon. News, 6, 34-39.

King, M.D., W.P. Menzel, P.S. Grant, J.S. Meyers, G.T. Arnold, S.E. Platnick, L.E. Gumley, S. Tsay, C.C. Moeller, M. Fitzgerald, K.S. Brown, and F.G. Osterwisch. 1995. Airborne Scanning Spectrometer for Remote Sensing of Cloud, Aerosol, Water Vapor and Surface Properties. Journal of Atmospheric and Oceanic Technology.

King, M.D., Y.J. Kaufman, W.P. Menzel, and D. Tanre. 1992. Remote sensing of cloud, aerosol, and water vapor properties from the Moderate Resolution Imaging Spectrometer (MODIS). IEEE Trans. Geosci. Remote Sens., 30, 2-27.

Moeller, C.C., O.K. Huh, H.H. Roberts, L.E. Gumley, and W.P. Menzel. 1993. Response of Louisiana coastal environments to a cold front passage. J. Coastal Res. 9, 434-447.

Nakajima, T. and M.D. King. 1990. Determination of the optical thickness and effective particle radius of clouds from reflected solar radiation measurements. Part I: Theory. J. Atmos. Sci., 47, 1878-1893.

Newcomer, J., D. Landis, S. Conrad, S. Curd, K. Huemmrich, D. Knapp, A. Morrell, J. Nickeson, A. Papagno, D. Rinker, R. Strub, T. Twine, F. Hall, and P. Sellers, eds. 2000. Collected Data of The Boreal Ecosystem-Atmosphere Study. NASA. CD-ROM.

Revercomb, H.E., H. Buijs, H.B. Howell, D.D. LaPorte, W.L. Smith, and L.A. Sromovsky. 1988. Radiometric calibration of IR Fourier transform spectrometers: Solution to a problem with the High-spectral resolution Interferometer Sounder. Appl. Opt., 27, 3210-3218. 
Running, S.W., C.O. Justice, V. Salomonson, D. Hall, J. Barker, Y.J. Kaufman, A.H. Strahler, A.R. Huete, J.P. Muller, V. Vanderbilt, Z.M. Wan, P. Teillet, and D. Carneggie. 1994. Terrestrial remote sensing science and algorithms planned for EOS/MODIS. Int. J. Remote Sens., 15, 3587-3620.

Sellers, P. and F. Hall. 1994. Boreal Ecosystem-Atmosphere Study: Experiment Plan. Version 1994-3.0, NASA BOREAS Report (EXPLAN 94).

Sellers, P. and F. Hall. 1996. Boreal Ecosystem-Atmosphere Study: Experiment Plan. Version 1996-2.0, NASA BOREAS Report (EXPLAN 96).

Sellers, P., F. Hall, and K.F. Huemmrich. 1996. Boreal Ecosystem-Atmosphere Study: 1994 Operations. NASA BOREAS Report (OPS DOC 94).

Sellers, P., F. Hall, and K.F. Huemmrich. 1997. Boreal Ecosystem-Atmosphere Study: 1996 Operations. NASA BOREAS Report (OPS DOC 96).

Sellers, P., F. Hall, H. Margolis, B. Kelly, D. Baldocchi, G. den Hartog, J. Cihlar, M.G. Ryan, B. Goodison, P. Crill, K.J. Ranson, D. Lettenmaier, and D.E. Wickland. 1995. The boreal ecosystem-atmosphere study (BOREAS): an overview and early results from the 1994 field year. Bulletin of the American Meteorological Society. 76(9):1549-1577.

Sellers, P.J., F.G. Hall, R.D. Kelly, A. Black, D. Baldocchi, J. Berry, M. Ryan, K.J. Ranson, P.M. Crill, D.P. Lettenmaier, H. Margolis, J. Cihlar, J. Newcomer, D. Fitzjarrald, P.G. Jarvis, S.T. Gower, D. Halliwell, D. Williams, B. Goodison, D.E. Wickland, and F.E. Guertin. 1997. BOREAS in 1997: Experiment Overview, Scientific Results and Future Directions. Journal of Geophysical Research 102(D24): 28,731-28,770.

Smith, W.L., R.O. Knuteson, H.E. Revercomb, W. Feltz, H.B. Howell, W.P. Menzel, N. Nalli, O. Brown, J. Brown, P. Minnett, and W. McKeown. 1995. Observations of the infrared radiative properties of the ocean - Implications for the measurement of sea surface temperature via satellite remote sensing. Submitted to Bull. Amer. Meteor. Soc.

Strabala, K.I., S.A. Ackerman, and W.P. Menzel. 1994. Cloud properties inferred from 8-12 mm data. J. Appl. Meteor., 33, 212-229.

Tsay, S.C., K. Stamnes, and K. Jayaweera. 1989. Radiative energy balance in the cloudy and hazy Arctic. J. Atmos. Sci., 46, 1002-1018.

Tsay, S.C., K. Stamnes, and K. Jayaweera. 1990. Radiative transfer in planetary atmospheres: Development and verification of a unified model. J. Quant. Spectrosc. Radiat. Transfer, 43, 133-148.

Twomey, S. and T. Cocks. 1982. Spectral reflectance of clouds in the near-infrared: Comparison of measurements and calculations. J. Meteor. Soc. Japan, 60, 583-592.

Wylie, D.P., W.P. Menzel, H.M. Woolf, and K.I. Strabala. 1994. Four years of global cirrus cloud statistics using HIRS. J. Clim., 7, 1972-1986.

\subsection{Archive/DBMS Usage Documentation}

None. 


\section{Glossary of Terms}

None.

\section{List of Acronyms}

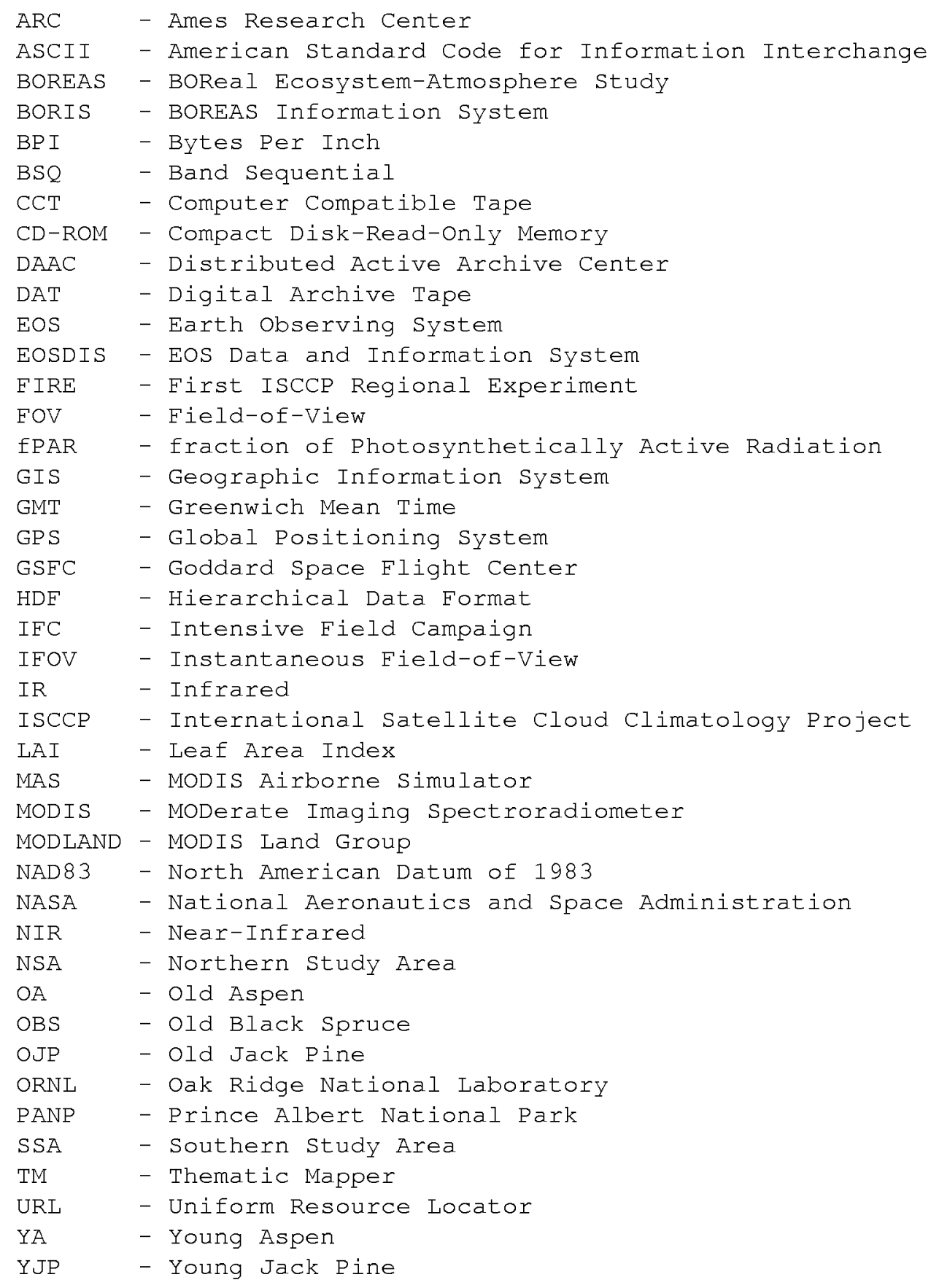




\section{Document Information}

20.1 Document Revision Date

Written: 25-Apr-1995

Last Updated: 06-Jul-1999

\subsection{Document Review Date}

BORIS Review: 09-Jun-1998

Science Review:

\subsection{Document ID}

\subsection{Citation}

When using these data, please include the following acknowledgment as well as citations of relevant papers in Section 17.2:

The level-1b MAS images were derived in a joint effort by both BORIS and MAS personnel at the National Aeronautics and Space Administration (NASA) Goddard Space Flight Center (GSFC). The contributions of the above individuals and agencies to completing this data set are greatly appreciated.

Also, cite the BOREAS CD-ROM set as:

Newcomer, J., D. Landis, S. Conrad, S. Curd, K. Huemmrich, D. Knapp, A. Morrell, J.

Nickeson, A. Papagno, D. Rinker, R. Strub, T. Twine, F. Hall, and P. Sellers, eds. Collected Data of The Boreal Ecosystem-Atmosphere Study. NASA. CD-ROM. NASA, 2000.

\subsection{Document Curator}

\subsection{Document URL}


Public reporting burden for this collection of information is estimated to average 1 hour per response, including the time for reviewing instructions, searching existing data sources, gathering and maintaining the data needed and completing and reviewing the collection of information. Send comments regarding this burden estimate or any other aspect of this collection of information including suggestions for reducing this burden, to Washington Headquaters Services, Directorate for Information Operations and Reports, 1215 Jefferson Davis Highway, Suite 1204, Arlington, VA 22202-4302, and to the Office of Management and Budget, Paperwork Reduction Project (0704-0188). Washington, DC 20503.

\begin{tabular}{|l|l|l|}
\hline 1. AGENCY USE ONLY (Leave blank) & 2. REPORT DATE & 3. REPORT TYPE AND DATES COVERED
\end{tabular}

4. TITLE AND SUBTITLE

September 2000

Technical Memorandum

Technical Report Series on the Boreal Ecosystem-Atmosphere Study (BOREAS)

BOREAS Level-1B MAS Imagery: At-sensor Radiance, Relative $\mathrm{X}$ and $\mathrm{Y}$

Coordinates

\section{AUTHOR(S)}

Richard Strub, Paul Hubanks, Jeffrey A. Newcomer, and Stephan Ungar Forrest G. Hall, Editor

\section{PERFORMING ORGANIZATION NAME(S) AND ADDRESS (ES)}

Goddard Space Flight Center

Greenbelt, Maryland 20771

5. FUNDING NUMBERS

923

RTOP: 923-462-33-01
9. SPONSORING / MONITORING AGENCY NAME(S) AND ADDRESS (ES)

National Aeronautics and Space Administration

Washington, DC 20546-0001
8. PEFORMING ORGANIZATION REPORT NUMBER

2000-03136-0

\section{SUPPLEMENTARY NOTES}

R. Strub and J. A. Newcomer: Raytheon ITSS; P. Hubanks: RDC

\begin{tabular}{l|l}
\hline 12a. DISTRIBUTION / AVAILABILITY STATEMENT & 12b. DISTRIBUTION CODE \\
Unclassified-Unlimited & \\
Subject Category: 43 & \\
Report available from the NASA Center for AeroSpace Information, \\
7121 Standard Drive, Hanover, MD 21076-1320. (301) $621-0390$.
\end{tabular}

13. ABSTRACT (Maximum 200 words)

For BOREAS, the MAS images, along with the other remotely sensed data, were collected to provide spatially extensive information over the primary study areas. This information includes detailed land cover and biophysical parameter maps such as PPAR and LAI. Collection of the MAS images occurred over the study areas during the 1994 field campaigns. The level-1b MAS data cover the dates of 21Jul-1994, 24-Jul-1994, 04-Aug-1994, and 08-Aug-1994. The data are not geographically/geometrically corrected; however, files of relative $\mathrm{X}$ and $\mathrm{Y}$ coordinates for each image pixel were derived by using the C-130 INS data in a MAS scan model. The data are provided in binary image format files.

\begin{tabular}{|c|c|}
\hline \multicolumn{2}{|l|}{$\begin{array}{l}\text { 14. SUBJECT TERMS } \\
\text { BOREAS, remo }\end{array}$} \\
\hline $\begin{array}{l}\text { 17. SECURITY CLASSIFICATION } \\
\text { OF REPORT } \\
\text { Unclassified }\end{array}$ & $\begin{array}{l}\text { 18. SECURITY CLASSIFICATION } \\
\text { OF THIS PAGE } \\
\text { Unclassified }\end{array}$ \\
\hline
\end{tabular}

19. SECURITY CLASSIFICATION OF ABSTRACT

Unclassified
15. NUMBER OF PAGES

28

16. PRICE CODE
20. LIMITATION OF ABSTRACT

UL 
